\title{
Revision and new data on the Early and Middle Miocene soricids (Soricomorpha, Mammalia) from Central and South-Eastern France
}

\author{
Marguerite Hugueney, Pierre Mein, Olivier Maridet
}

\begin{abstract}
New or poorly known Soricids from the Early Miocene of Central France (Limagne d'Allier) and from the Middle Miocene of South-Eastern France (near Lyon) are studied; one new genus (Viretia) and a new species (Carposorex burkarti) are described. The soricid assemblages of the Early and late Early/Middle Miocene localities are totally different from each other and new information about appearance and evolution of the taxa are introduced. The following are lists of studied taxa for the beginning of the Early Miocene: Clapasorex bonisi, Clapasorex aff. sigei, Carposorex burkarti nov. sp., Soricella cf. discrepans, Oligosorex aff. antiquus and Crocidosoricinae indet, and for the late Early/Middle Miocene Dinosorex sansaniensis, Dinosorex pachygnathus, Heterosorex delphinensis, Miosorex desnoyersianus, Miosorex grivensis, Lartetium dehmi, Lartetium ziegleri, Turiasorex pierremeini, Viretia nov. gen. gracilidens, Paenelimnoecus micromorphus, Paenelimnoecus crouzeli and Hemisorex robustus.
\end{abstract}

Keywords Soricidae, Heterosoricinae, Crocidosoricinae, Allosoricinae, Paenelimnoecinae, Soricinae, Early Neogene, France, Central Massif, Region of Lyon, New taxa

M. Hugueney (corr. author), P. Mein, O. Maridet Laboratoire de géologie de Lyon: terre, planètes, environnement, UMR CNRS 5276, université Lyon 1, 43, boulevard du 11-novembre, 69622 Villeurbanne cedex, Francee-mail: marguerite.hugueney@univ-lyon1.frP. Meine-mail: pierre.mein@univ-lyon1.fr

O. Maridet

Key Laboratory of Evolutionary Systematics of Vertebrates, Institute of Vertebrate Paleontology and Paleoanthropology, Chinese Academy of Sciences, Beijing 100044, Chinae-mail: olivier.maridet@ivpp.ac.cn

\section{Introduction}

The Early and Middle Miocene fossil record of Central and South-Eastern France comprises numerous and often very rich localities, either from stratified sediments or fissurefillings, all of which yielded Soricids. The initial studies of these taxa date back several decades and most of them have never been restudied since then. Furthermore, newly discovered specimens have never been described. We survey and update taxa that belong to the subfamilies: Heterosoricinae, Allosoricinae, Paenelimnoecinae, Soricinae and Crocidosoricinae, the last of which is paraphyletic (as suggested by Furió et al. 2007; Hugueney and Maridet 2011 and others) but it is convenient to separate the taxa whose phylogenetic positions are uncertain from those whose assignment is certain.

Biochronologic background of Limagne Basin localities

The Limagne Basin yielded the types of several soricid genera (Crocidosorex Lavocat, 1952, Oligosorex Kretzoi, 1959, Meingensorex Hugueney and Maridet, 2011; see Fig. 1). The basin includes for instance the well-known locality Montaigu-le-Blin (Allier; reference locality for MN2a), but surrounding localities are not of exactly the same age (Hugueney et al. 2006) and yielded different taxa of soricids. We present here the soricids of Gannat and Chavroches, localities never studied before and whose age is a little older than Montaigu-le-Blin.

The soricids of Gannat come from three superposed levels at the top of a quarry which was excavated by M. Hugueney and was subsequently destroyed due to mining activities; they constitute three different localities: (1) the lower level (locality called Gannat-81, G-81) is located 
roughly $6 \mathrm{~m}$ beneath the top of the quarry and is irregularly stratified. (2) The intermediate level (locality called Gannat-sommet, G-som) is located about $2 \mathrm{~m}$ higher (but intercalated between stromatolitic constructions). The eomyids taxa produced by these localities display a morphology which is more advanced than those of Coderet (MP 30), but a little less advanced than those of Paulhiac (MN1) indicating an intermediate age between the two localities. (3) The upper layer (locality called Gannat-sup., G-sup), near the top of the quarry, yielded a relatively poorly diversified fauna. Plesiosminthus myarion Schaub, 1930 is the most abundant species recovered from this layer (Plesiosminthus is absent in the two lower layers). P. myarion is a species characteristic of the Early Miocene as opposed to $P$. schaubi Viret, 1936 from the Late Oligocene of Coderet (Hugueney 1997). This layer also yielded Cainotherium miocaenicum Crusafont et al., 1955, a minute cainotheriid, hitherto only known from and abundant in Miocene, also reported in lower levels (G-81 and G-som; Berthet 2003). The three localities of Gannat can thus be ascribed to the lowermost Miocene (MN1).

The fossils of Saulcet were collected by J. Hürzeler around 1930 and are mainly housed in the Natural History Museum Basel, but some are in the Lyon Museum. Their age is difficult to estimate, MN1/MN2a, but it is younger than Gannat and older than Chavroches.

The locality Chavroches comprises irregularly stratified sandy/argillaceous layers which are overlain by stromatolitic formations embedded in identical sediments. The small mammals are recovered from the interstitial deposits and are often strongly encrusted and difficult to observe. This locality was also excavated by J. Hürzeler in 1930 but the soricid material was never studied; in addition, D. Berthet recently made new excavations that yielded abundant material. The eomyids of this locality indicate a correlation MN2a but slightly older than Montaigu-le-Blin (Hugueney et al. 2006).

The locality of Cluzel 1 yielded eomyids which correlate MN2a a bit younger than Chavroches but slightly older than the lower levels of Montaigu-le-Blin (Hugueney et al. 2006).

Biochronologic background of Lyon region localities

In the neighbourhood of Lyon, the two famous localities Vieux-Collonges and La Grive-Saint-Alban which correlate with the late Early and Middle Miocene, respectively, yielded rich micromammal faunas. Vieux-Collonges, the older of the two, is an isolated fissure-filling in a limestone quarry near the village of Vieux-Collonges (Mein 1958). Based on the evolutionary stages of the cricetid rodents its fauna can be ascribed to MN5 (Mein 1975; Maridet 2003).

La Grive Saint Alban was exploited for limestone; several quarries were worked at the beginning of the 20th century. The fissures in the limestone are filled with red clay which contains rich faunas of small and large mammals (Mein and Ginsburg 2002). These localities were excavated by P. Mein, but nowadays most of the quarries have disappeared. Each fossiliferous fissure is treated as a separate locality, with noticeably different ages (Mein and Ginsburg 2002; Maridet 2003), and is distinguished with a letter and a number (La Grive L3, L5, L7, M; the former being the reference locality for the MN7-8). La Grive L3 and L5 are the oldest fissure-fillings in the area of $\mathrm{La}$ Grive-Saint-Alban as indicated by the occurrence of Democricetodon aff. brevis (Schaub, 1925) of which the morphology is intermediate between D. gracilis Fahlbusch, 1964 of Sansan (see Maridet and Sen 2012) and D. brevis from La Grive M and L7 (Maridet 2003). However, the occurrence of the genus Hispanomys Mein and Freudenthal, 1971 in La Grive L3 and L5 (López-Antoñanzas and Mein 2009) suggests a correlation of the two localities to biozone MN7-8 rather than to MN6 (reference locality Sansan). The very similar faunal composition of La Grive L3 and L5 suggest a close age, possibly 'early' MN7-8. Mein and Ginsburg (2002), however, suggested that La Grive L3 might be slightly older than La Grive L5. The two other localities La Grive L7 and M yielded similar faunas indicating a close age. However, as demonstrated by Maridet (2003), the species Spermophilinus bredai von Meyer, 1848, Heteroxerus grivensis (Major, 1893), Eomuscardinus vallesiensis Hartenberger, 1966 and Democricetodon (Falhbuschia) larteti (Schaub, 1925), which increase in size over time, are slightly larger in La Grive $\mathrm{M}$ than in La Grive L7 suggesting that La Grive M is the youngest of the two.

\section{Materials and methods}

The classification follows Furió et al. (2007) and the terminology and measurements follow Reumer (1984). For the dental formula we follow the quotation of Dannelid (1998) counting 'upper/lower' incisor, antemolars, premolars and molars (e.g. genus Sorex 1.5.1.3/1.1.1.3). Upper and lower cheek-teeth are indicated by upper case (I, A, P, M) and lower case letters (i, a, p, m), respectively. Other abbreviations are maxilla $(\mathrm{Mx})$ and mandible (Md). Measurements are given in millimetres: L, maximal length; W, maximal width; $\mathrm{H}$, maximal height; $\mathrm{TrW}$, trigonid width; TaW, talonid width. Mandibular measurements are taken in buccal view unless otherwise indicated. In addition, $\mathrm{H} / \mathrm{m} 2$ 
designates the height of the mandibles under $\mathrm{m} 2$. Measurement tables are synthetic ones but details of measurements are available on request.

SEM photographs of the material from Vieux-Collonges and La Grive were taken by P. Bert and D. Jammot (Dijon University) a long time ago but have not been previously published.

Institutional abbreviations University Lyon1 (FSL), Museum of Lyon (ML or MLMC), Musée national d'Histoire naturelle de Paris (MNHN); Naturhistorisches Museum of Basel (NMB).

\section{Systematic palaeontology}

Class Mammalia Linnaeus, 1758

Order Soricomorpha Gregory, 1910

Family Soricidae G. Fischer, 1814

Subfamily Heterosoricinae Viret and Zapfe, 1952

Genus Dinosorex Engesser, 1972

Type species Dinosorex pachygnathus Engesser, 1972

Type locality Anwil (Switzerland), late Middle Miocene (MN7-8)

Dinosorex sansaniensis (Lartet, 1851)

Material Vieux-Collonges: FSL 66665, A2; MLMC 409, left mandible with $\mathrm{i}, \mathrm{m} 1, \mathrm{~m} 2$ and $\mathrm{m} 3$ (i crown length $=3.87$, vertical diameter $=1.92$, transversal diameter $=1.28, \mathrm{~L}$ $\mathrm{m} 1-3=5.96$; height under $\mathrm{m} 3=2.75$ ), FSL 66666, right $\mathrm{m} 1$.

Measurements Table 1

Description The tips of molar cusps are pigmented and the incisor is darker than the molars; this pigmentation is more visible on the buccal side. According to Engesser (2009), this species possesses four upper antemolars, A2 being the only triangular-shaped antemolar. The A2 from Vieux-Collonges (FSL 66665) displays a triangular shape. On the mandible (MLMC 409), the number of antemolars is difficult to estimate because the upper part of the mandible is broken. Despite the fact that Vieux-Collonges

Table 1 Measurements of Dinosorex sansaniensis from Vieux-Collonges (in $\mathrm{mm}$ )

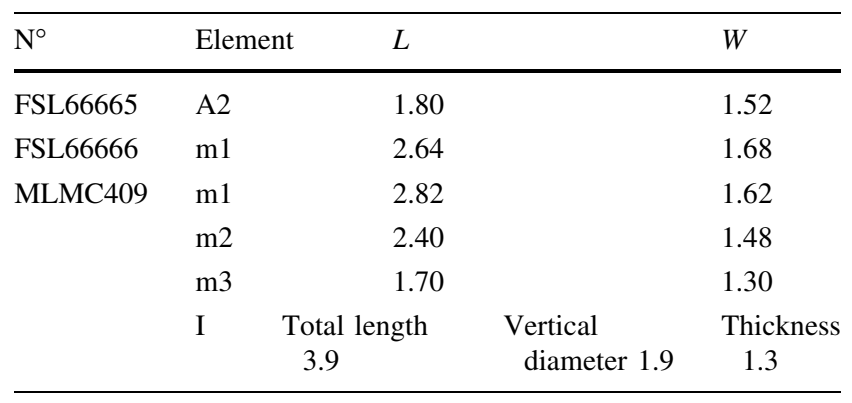

(MN5) is older than Sansan (MN6, S-W France), the comparison of the mandible from Vieux-Collonges with the numerous mandibles recovered from Sansan shows no differences, either in length or in morphology. This species was precisely described in Engesser (2009, p. 9-13) and the mandible, the incisor and the condyle are figured (Figs. 1a-c, 3a-c).

Dinosorex pachygnathus Engesser 1972

Figure 1a-c

Material The bulk of the material comes from the La Grive L7 fissure. But other fissures from La Grive L3 and $\mathrm{M}$ produced comparable material. All these fissures correlate to MN7-8. Fissure L3: FSL 66657-66660, four isolated teeth (M2, m2, m3). Fissure L7: FSL 66641-FSL 66656, two maxilla and six mandibles, plus several isolated teeth (I, A, P4, M1, M2, M3, i, a, m1, m2 and m3). Fissure M: FSL 66661-66664, one maxilla and two mandibles, plus isolated $\mathrm{P} 4, \mathrm{p} 4$ and $\mathrm{m} 1$.

Measurements Table 2

Description The upper incisor of Dinosorex pachygnathus was figured by Engesser (1972). As in the Anwil locality, the incisors are larger than those of Heterosorex delphinensis and the incisor tip is slightly bifid: on the side of the main point, there is a secondary anterolabial tip. The main point is prolonged by a coloured crest joining the basal cingulum. The lingual edge furrow is wide and deep. The labial side is lined by a slight basal cingulum.

The labial side of M3 has no post-metacone ridge and does not show a W (parastyle-paracone-mesostyle-metacone). From the metacone, a posterolingual ridge closes the posterior edge; it turns on the lingual edge to the protocone base. The protocone, very open $\mathrm{V}$-shaped, shows a branch reaching the anterior edge at the back of the paracone. This tooth has a great central transverse valley; its lower point is at the centre of the tooth. The labial edge shows a small cingulum between the parastyle and the mesostyle.

The morphology of the other teeth is identical to the descriptions given by Engesser $(1972,1975)$.

Discussion The main differences between D. pachygnathus and $H$. delphinensis are (1) the number of upper antemolars: three in $H$. delphinensis and four in D. pachygnathus, (2) the morphology of the P4: this tooth is triangular in H. delphinensis with a very long buccal edge, but rectangular for D. pachygnathus with the buccal and lingual edges about the same length, (3) the morphology of the mandible: the upper edge of the ascending ramus is located posteriorly to the middle of the masseteric fossa in $H$. delphinensis, whereas it is located anteriorly in D. pachygnathus; furthermore, the inferior edge of the masseteric fossa is below the molar row in $H$. delphinensis but above it in $D$. pachygnathus. 


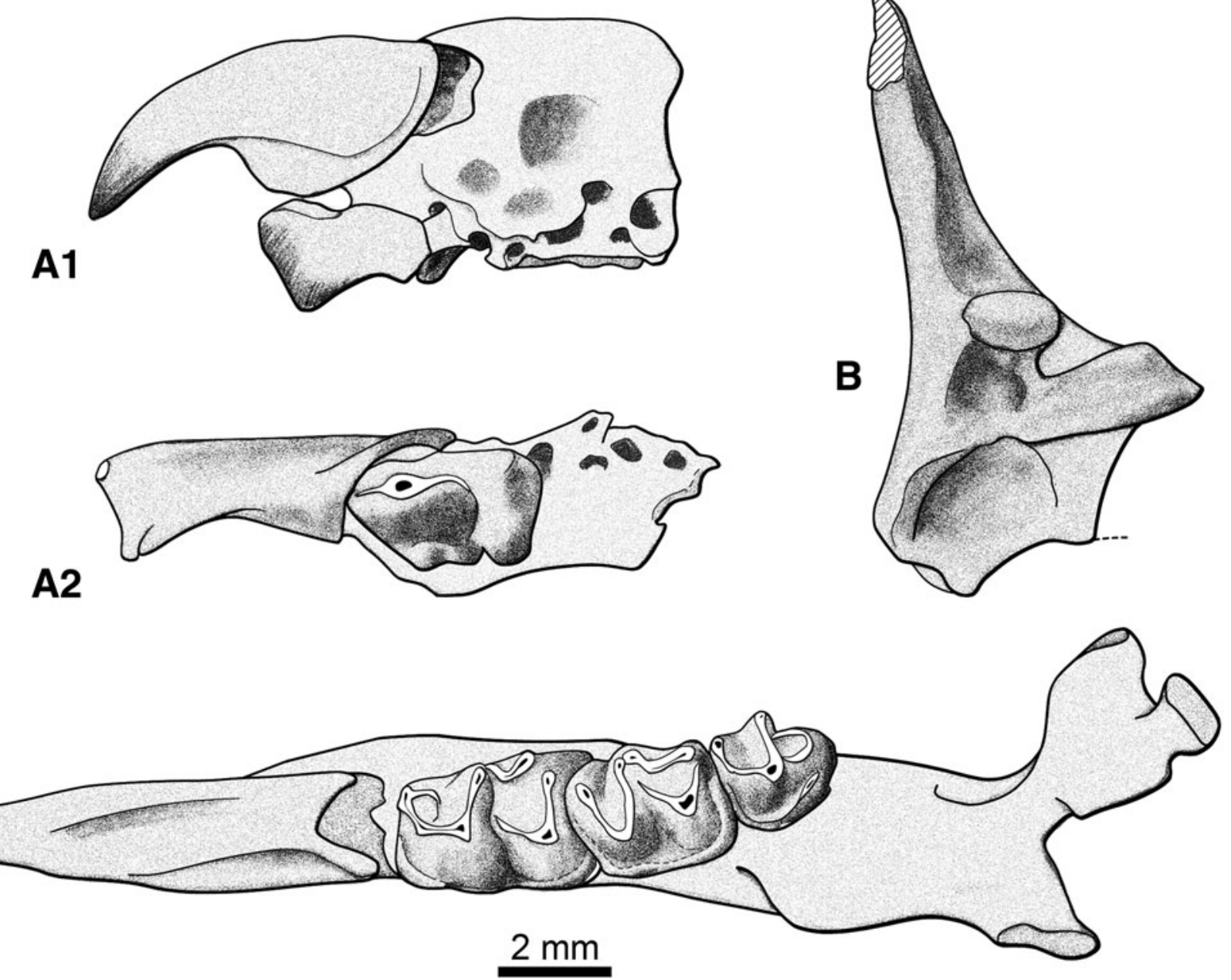

Fig. 1 Dinosorex pachygnathus Engesser, 1972 from La Grive L7 (a, c) and $\mathrm{M}(\mathbf{b})$ : a left maxillary fragment with I and one antemolar A1, FSL 66641(a1 labial view, a2 occlusal view); b left ascending ramus

Genus Heterosorex Gaillard, 1915

Type species Heterosorex delphinensis Gaillard, 1915

\section{Heterosorex delphinensis Gaillard, 1915}

Holotype Muzzle and associated mandible ML Lgr.209 (Gaillard 1915; Figs. 4, 5, 6) and figured in Viret and Zapfe (1952, Fig. 11a-c); from La Grive-Saint-Alban, exact origin unknown.

Material The holotype is the only material referred to this species.

Description The three upper antemolars of H. delphinensis decrease in size from A1 to A3. The mandible possesses only two alveoli before $\mathrm{m} 1$, one for $\mathrm{p} 4$ and one for a1.

Discussion Since the study of Gaillard (1915), no new material from La Grive has been ascribed to this species. The precise origin of these specimens is completely unknown and, since 1915, some quarries have been destroyed. The only complementary indication is the presence of a small glirid Miodyromys hamadryas with condyle, FSL 66663 (posterior view); c left mandible with incisor and $\mathrm{m} 1-\mathrm{m} 3$, FSL 66652 (occlusal view)

hamadryas (Major 1899), stored in the collections of the British Museum (M5298a), with the same imprecise origin (likely the same fissure-filling as $\mathrm{H}$. delphinensis). $\mathrm{H}$. delphinensis is unknown in the Middle Miocene, faunas from La Grive fissures, but Miodyromys hamadryas hamadryas (also known for instance in Germany from Langenmoosen, MN5) proves that older fissure fillings where excavated in the area of La Grive at the beginning of the 20th century.

According to a reduction of the number of antemolars with time, $H$. delphinensis is so far the most derived species of the genus with only $3 / 1$ antemolars and it is also the last record of this genus.

Remarks Heterosoricinae are rare in the faunas studied here. Although they were present in the Upper Oligocene, they are almost unknown in the Earliest Miocene of Limagne, Heterosoricinae indet. from Saulcet (MN1/2) being the only taxon reported so far. For the Middle Miocene the subfamily comprises only three species: $D$. sansaniensis, $D$. pachygnathus and $H$. delphinensis. Among the localities 
Table 2 Measurements of Dinosorex pachygnathus from La Grive localities L3, L7 and M (in mm)

\begin{tabular}{|c|c|c|c|c|c|c|c|c|}
\hline & \multirow[t]{2}{*}{ Locality } & \multirow[t]{2}{*}{$N$} & \multicolumn{2}{|l|}{$L$} & \multicolumn{2}{|l|}{ TrW } & \multicolumn{2}{|l|}{ TaW } \\
\hline & & & Range & Mean & Range & Mean & Range & Mean \\
\hline $\mathrm{m} 1-3$ & L7 & 1 & - & 5.80 & - & - & - & - \\
\hline \multirow[t]{2}{*}{$\mathrm{m} 1$} & L7 & 11 & $2.45-2.74$ & 2.59 & $1.43-1.75$ & 1.56 & $1.57-1.85$ & 1.69 \\
\hline & M & 2 & $2.76-2.80$ & 2.78 & $1.53-1.77$ & 1.65 & $1.66-1.88$ & 1.77 \\
\hline \multirow[t]{3}{*}{$\mathrm{m} 2$} & L3 & 1 & - & 2.38 & - & 1.59 & - & 1.47 \\
\hline & L7 & 8 & $2.20-2.54$ & 2.35 & $1.50-1.73$ & 1.59 & $1.33-1.62$ & 1.50 \\
\hline & M & 1 & - & 2.23 & - & 1.55 & - & 1.58 \\
\hline \multirow[t]{2}{*}{$\mathrm{m} 3$} & L3 & 1 & - & 1.85 & - & 1.46 & - & 1.02 \\
\hline & L7 & 5 & $1.58-1.89$ & 1.70 & $1.03-1.30$ & 1.18 & $0.92-1.04$ & 0.96 \\
\hline P4-M2 & L7 & 1 & - & 6.10 & - & - & - & - \\
\hline A1 & L7 & 1 & - & 2.45 & - & - & - & - \\
\hline \multirow[t]{2}{*}{ P4 } & L7 & 1 & - & 2.07 & - & 2.58 & - & - \\
\hline & M & 1 & - & 2.12 & - & 2.20 & - & - \\
\hline M1 & L7 & 1 & - & 2.26 & - & 2.65 & - & - \\
\hline \multirow[t]{4}{*}{ M2 } & L3 & $2 / 1$ & $2.23-2.23$ & 2.23 & $1.86-2.46$ & 2.16 & $1.77-1.77$ & 1.77 \\
\hline & L7 & 1 & - & 2.13 & - & 2.53 & - & - \\
\hline & Locality & $N$ & $L$ & & $H$ & & $H / \mathrm{m} 2$ & \\
\hline & & & Range & Mean & Range & Mean & Range & Mean \\
\hline Md & M & 2 & - & - & - & - & $3.23-3.40$ & 3.31 \\
\hline I & L7 & 1 & - & 5.07 & - & 2.16 & - & - \\
\hline
\end{tabular}

studied here, Vieux-Collonges is the only locality which yielded a few specimens of Dinosorex sansaniensis.

Subfamily Crocidosoricinae Reumer, 1987

Genus Clapasorex Crochet, 1975

Type species Clapasorex sigei Crochet, 1975

Type locality Bouzigues 1 (France, Hérault), Early Miocene (MN2b)

Clapasorex bonisi Crochet, 1975

Figure 2a-f, h-k

Material and measurements. Gannat-81: I, P4,M1,M2, FSL 98200-98204; mandibular fragments, FSL 98205-98208; isolated i and m1-2, FSL 98209-98210. Gannat-sommet: isolated incisors, FSL 98211; mandibular fragment with p4-m2, FSL 98212; isolated teeth, FSL 98213-98219 (Table 3).

Description Very small-sized soricid (L m1-3= 2.62-2.76) which possesses apparently three single-rooted antemolars anterior to the double-rooted p4. The antemolars are unknown, but the second alveolus behind the incisor is proportionally large and seems to contain the roots of a single-rooted a 2 and of a minute single-rooted a3 hidden under $\mathrm{p} 4$. Consequently the lower dental formula is 1.3?.1.3. All teeth are pigmented.

The lower part of the mandible (FSL 98212; Fig. 2f) is slightly damaged under the molars, but its better preserved anterior part shows a large alveolus for a1, a hardly smaller one for a2 and 3 under the small p4 which is very procumbent. The mental foramen is located directly anterior to the posterior root of $\mathrm{p} 4$; the anterior part of the mandible remains high but is very short so that the posterior border of the alveolus of $i$ is situated rather close to the anterior part of $\mathrm{p} 4$. Another mandible with m1-3 shows part of the ascending ramus, which is almost perpendicular to the horizontal branch with an inferior undulating base and a very long angular process, denticulated on its upper part.

Among the lower teeth, six isolated lower incisors were found in G-som: all are bicuspulate and small, faintly falciform and with a marked posterocuspule (FSL 98211). Only one p4 on a mandible is known in G-som; it is rather worn and its apex only shows a flat triangular surface with two divergent symmetrical posterior crests ending before the basal cingulum. The rather high cingulum surrounds the entire tooth but disappears under the anterior emargination; a small median posterocuspule is present.

The morphology of the molars is characterised by acute tubercles lying on a massive base and a thin but marked basal cingulum, only slightly enlarged anteriorly; the internal cingulum is also present. The length of $\mathrm{m} 1$ is not very different of that of $\mathrm{m} 2$. The oblique crest is ascending on the posterior wall of the trigonid; the entocristid is short but well developed and acute on $\mathrm{m} 1$, a little rounded and 

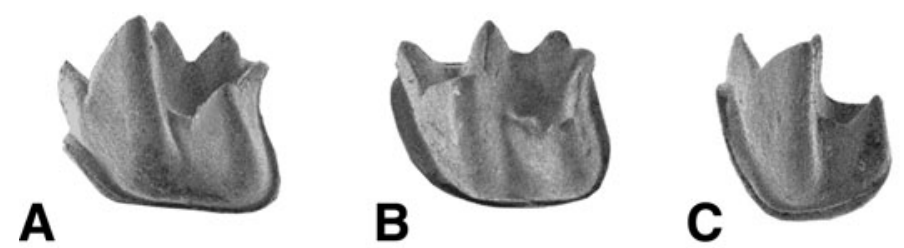

$1 \mathrm{~mm}$

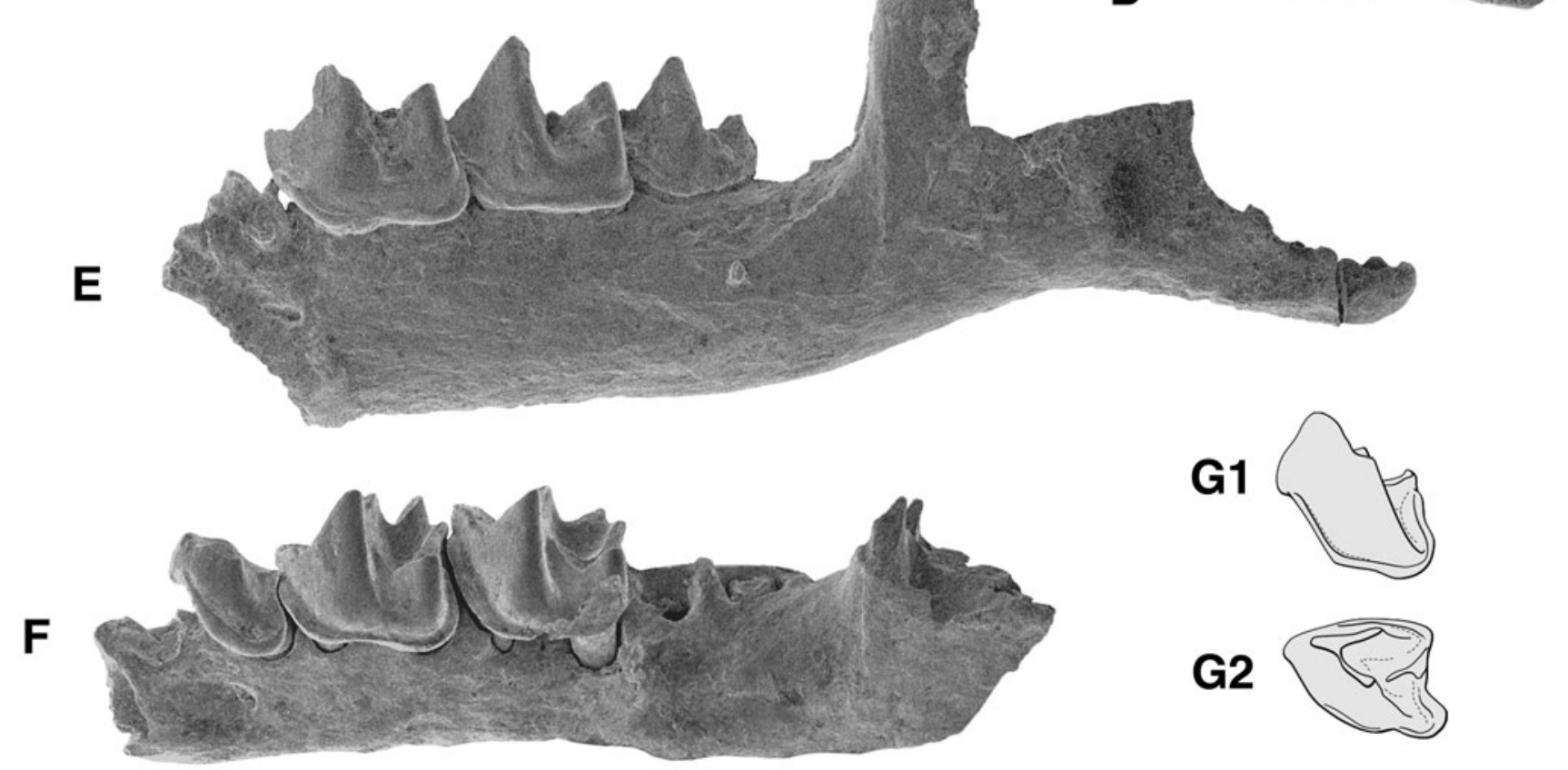

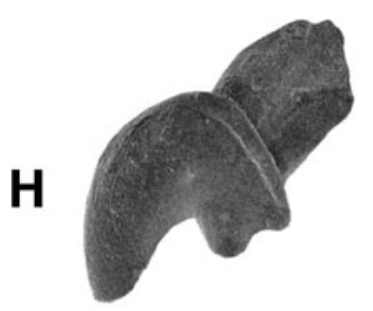

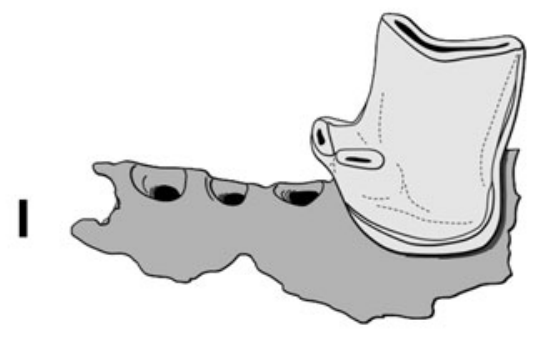

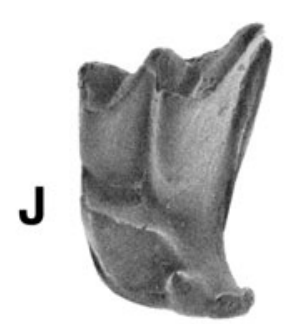

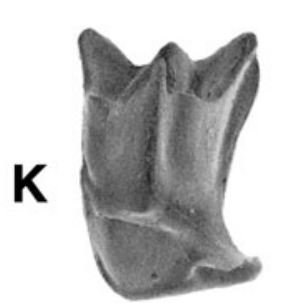

Fig. 2 Clapasorex bonisi from Gannat (a-f, h-k) and Clapasorex aff. sigei from Cluzel 1 (g): a left m1, FSL 98213 (labial view, G-som.); b left m2, FSL 98214 (labial view, G-som.); c left m3, FSL 98215 (labial view, G-som.); d left i, FSL 98211 (labial view, G-som.); e left mandibular fragment with m1-3, FSL 98205 (labial view, G-81); f left mandibular fragment with p4-m2, FSL 98212

lower on $\mathrm{m} 2$; the talonids of $\mathrm{m} 1-2$ are well developed; the talonid of $\mathrm{m} 2$ is about as large as the trigonid. The talonid of $\mathrm{m} 3$ is closed by two low crests ascending to only one cuspide, the hypoconid.

The upper incisor is very small, the buccal side of its wide and flattened root showing only a labial furrow; the apex is well rounded but points anteriorly; the talon is also rounded and the buccal cingulum is well marked.

The antero-labial border of P4 (FSL 98201) is rounded; the parastyle is labially located, next to paracone and (labial view; G-som.); g left p4, FSL 98222 (g1 labial view, g2 occlusal view, Cluzel1); h left I, FSL 98200 (labial view; G-81); i left P4 on maxillary fragment, FSL 98201 (palatal view, G-81); j left M1, FSL 98202 (occlusal view, G-som.); k left M2, FSL 98203 (occlusal view, G-81)

protocone; a short parastylar crest joins the base of the paracone; hypocone and posterior emargination are absent; a faint and regular cingulum surrounds the hypoconal flange.

M1 is short and compressed antero-posteriorly, the posterior emargination is lingual and faint and hypoconal flange is short. Tubercles are acute and the labial border is clearly indented; the parastyle shows a short distal crest. The preprotocrista ends a little before the paracone and the postprotocrista goes abruptly down and ends anteriorly to a 
Table 3 Measurements of the lower and upper dentitions of Clapasorex from Gannat (in $\mathrm{mm}$ )

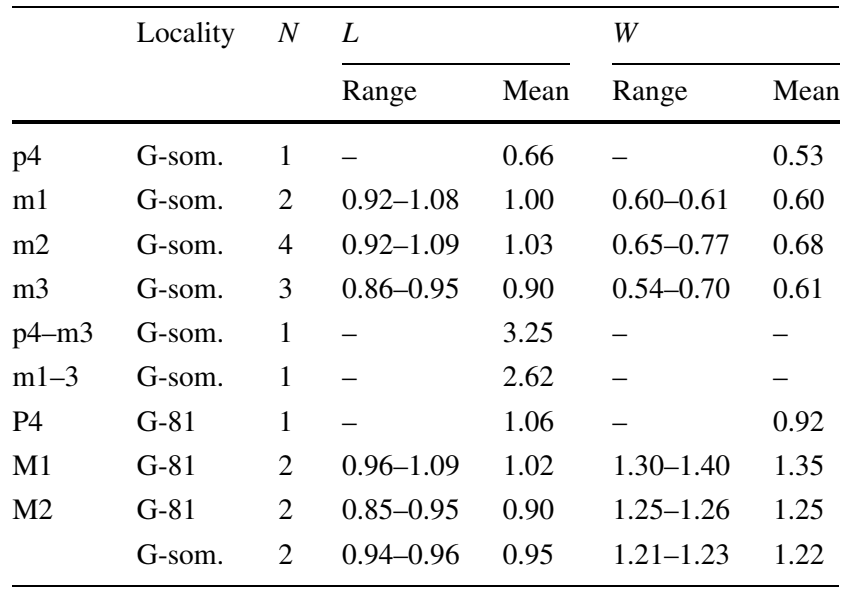

G-som. Gannat sommet

small but well-rounded hypocone with distal cingulum; a thin but well-marked cingulum starts before hypocone base toward the anterior part of the tooth. M2 (FSL 98203) is a little smaller than M1, also with a more symmetric $\mathrm{W}$-shaped wear facet; the preprotocrista is ascending labially under the paracone; the heel is short with a very faint tubercle and an internal cingulum. M3 is unknown.

Discussion The material from Gannat is homogeneous regarding size and, even if a part of the dentition, the condyles and the skull are missing, facilitates the distinction of the main characteristics of the genus Clapasorex: the shape of the anterior part of the mandible and of the antemolars alveoli, the pattern of premolars and molars (and particularly the upper molars with lingual cingulum, the small but double-rooted $\mathrm{p} 4$, the moderate width of $\mathrm{m} 1-2$ talonids). Furthermore, the tiny size is similar to that of the coeval Clapasorex bonisi from Paulhiac (MN1; L m1-3 = 2.82).

Remarks The lower incisor of Clapasorex from Gannat is morphologically not very different from that of Oligosorex even if it is a little more falciform and much smaller; it differs from the Clapasorex sigei incisor figured by Crochet (1975) in having only two denticles. It is however possible, based on the illustration published by Crochet (1975) that some of the five mentioned denticles of Clapasorex sigei are an artefact due to the preservation.

In the description of the $\mathrm{p} 4$ of $C$. sigei, Crochet (1975) notices that the lingual crest of $\mathrm{p} 4$ disappears always rapidly but, on his Fig. 11, this lingual crest is very long and was distinguished by Reumer (1987) as a special type of Crocidosoricinae. In fact, the pattern of the $\mathrm{p} 4$ is variable on the material from Bouzigues: in Lyon collections, in some $\mathrm{p} 4$ the lingual crest seems to be longer than the labial one, but the p4 often shows two subequal divergent crests or even a junction between the postero-labial crest and the postero-cingulum (see $C$. aff. sigei below).
The occurrence of $C$. bonisi in Gannat, whereas no equivalent morphology is known in the European Upper Oligocene, suggests that Clapasorex is likely an immigrant genus arriving in Europe at the beginning of the Miocene.

The teeth of Crocidosorex sp. from Ulm-Westtangente (MN2a; Ziegler 1989) show roughly the same length as C. bonisi from Gannat but the width of the German specimens seems to be smaller. The talonid of $\mathrm{m} 3$ is also more rectangular and the upper molars have no internal cingulum in these German specimens; we consequently agree that they do not belong to the genus Clapasorex. As well as the small soricid from Anatolia (Soricid III; MN1; van den Hoek Ostende 2001): its size is identical to that of $C$. bonisi and its morphology quite similar, but the upper molars show only "a short and narrow cingulum against the anterior flank of the protocone" and the upper incisor shows a strong anterior curve and its apex points backward.

Clapasorex aff. sigei Crochet, 1975

Figure $2 \mathrm{~g}$

Material and measurements Chavroches: NMB CHAV 1127, $\mathrm{Md}(\mathrm{L} \mathrm{m} 1-3=3.25 ; \mathrm{p} 4=0.58 \times 0.54 ; \mathrm{m} 1=$ $1.20 \times 0.78 ; \quad \mathrm{m} 2=1.17 \times 0.77 ; \quad \mathrm{m} 3=0.96 \times 0.67)$. Cluzel 1: FSL 98222, p4 $(0.70 \times 0.51)$; FSL 98223, m2 $(1.09 \times 0.82)$; FSL 98224 , M3 $(0.95 \times 1.19)$.

Description The Chavroches sample includes a small mandible (NMB CHAV 1127) with a very short anterior part. The specimen possesses a two-rooted and very short p4 with triangular apex, three one-rooted antemolars and teeth with thin and regular cingula.

The locality Cluzel 1 yielded also a few small teeth. The p4 (Fig. 2g) shows a particularity: the postero-labial and postero-lingual arms are sub-equal, each with a fold joining the basal cingulum, but, a crest starting from the median postero-cuspule joins the postero-labial crest in its middle height, creating a postero-lingual basin.

Discussion The morphology of these teeth corresponds to Clapasorex; they are a little larger than the teeth of Gannat and their size fits better that of $C$. sigei. Moreover, in Bouzigues some p4 show the same pattern as that of Cluzel 1.

Starting from MN2, the local lineage of Clapasorex grows larger and reaches a size even larger than $C$. sige $i$

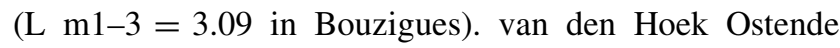
(2003) notices a size increase from MN1 to MN3, as the species C. alvarezae (MN3, Ramblar 3, Spain) is larger than $C$. sigei. C. bonisi from Gannat (MN1) and the more recent $C$. aff. sigei from Chavroches and Cluzel 1 (MN2) could confirm this evolutionary trend and could support the hypothesis formulated by van den Hoek Ostende (2003) that these three species of Clapasorex could belong to a same lineage, lineage that would become extinct after the MN3. 

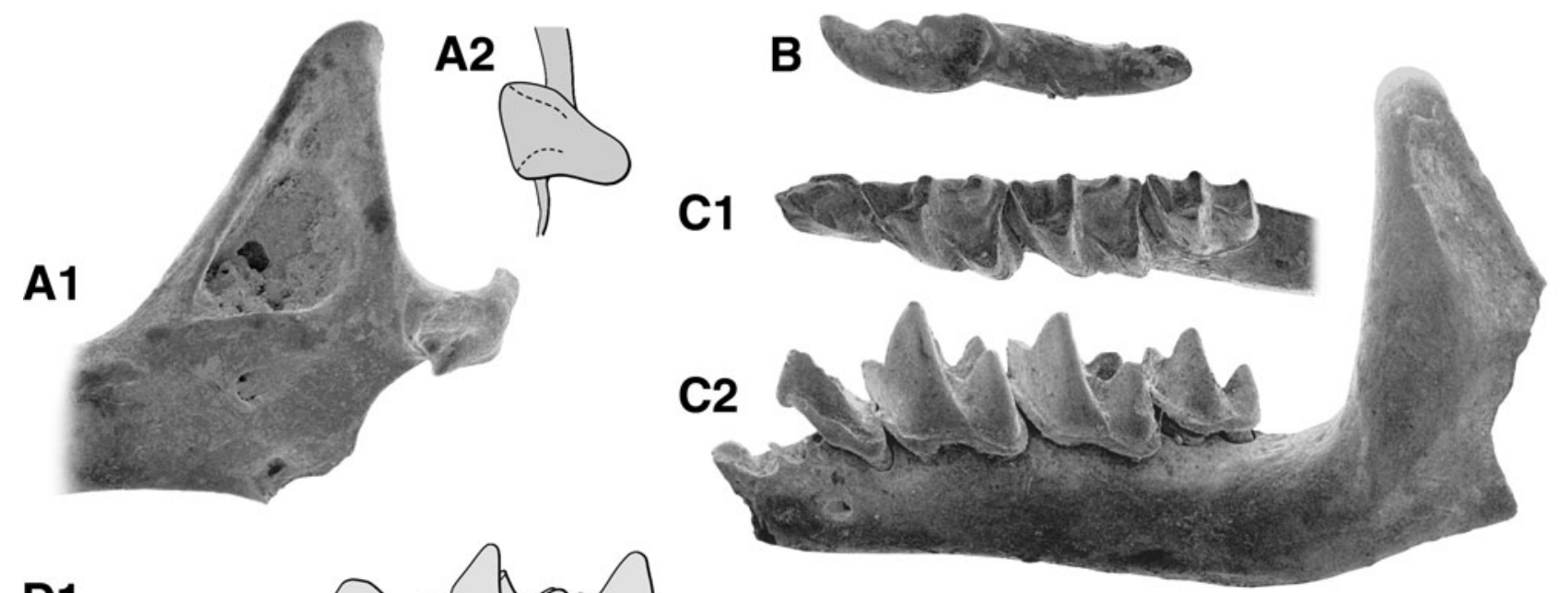

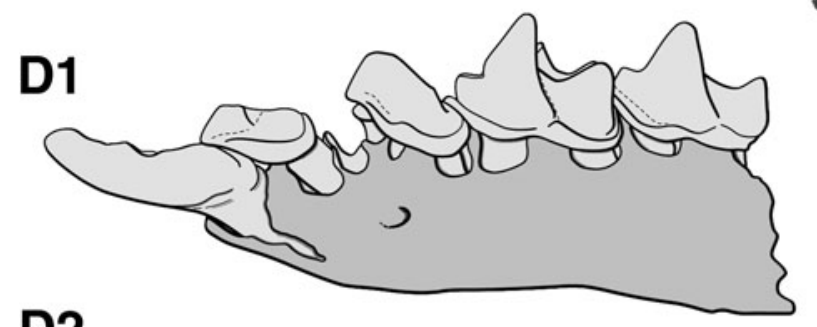

D2

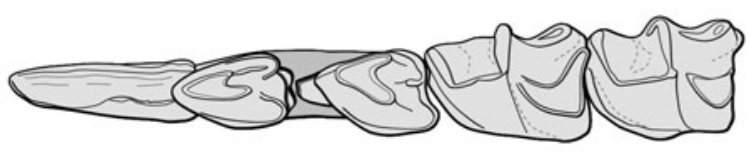

D3

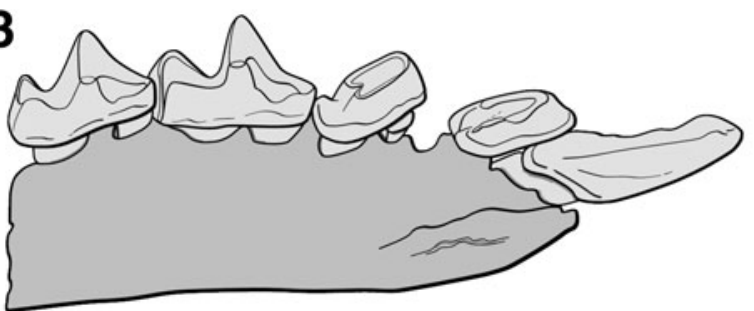

Fig. 3 Carposorex burkarti nov. sp. from Chavroches (a-f) et Carposorex aff. burkarti from Gannat sup. (g): a left (reversed) mandibular fragment with internal temporal fossa and condyle, ML CHA 20.270301 (a1 lingual view, a2 sketch of condyle in caudal view); b left i, ML CHAV 20.270302 (labial view); c left mandible with $\mathrm{p} 4-\mathrm{m} 3$ and fragmentary ascending ramus, ML CHAV

\section{Genus Carposorex Crochet, 1975}

Type species Carposorex sylviae Crochet, 1975

Type locality Laugnac (France, Lot-et-Garonne), Early Miocene (MN2b)

Carposorex burkarti nov. sp.

Figure $3 \mathrm{a}-\mathrm{f}$

Holotype left Md with $\mathrm{p} 4-\mathrm{m} 3$ and fragmentary ascending ramus (ML CHAV 20.270300; Fig. 3c)

Type-locality Chavroches (France, Allier), Early Miocene (MN2a)

Etymology Dedicated to Burkart Engesser appreciating his great contributions to mammalian palaeontology and especially to our knowledge of soricids.

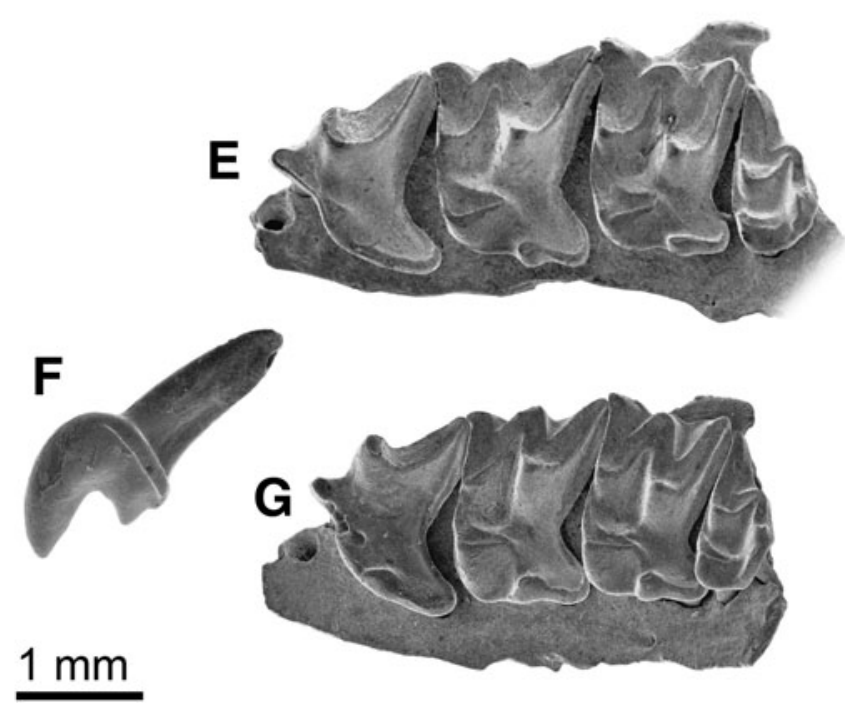

20.270300, holotype (c1 occlusal view, c2 labial view); d left mandible with I, a1, a3 and p4-m2, ML CHAV 20.270303 (d1 labial view, $\mathbf{d} 2$ occlusal view, $\mathbf{d} 3$ lingual view); e left maxilla with P4-M3, ML CHAV 20.270304 (palatal view); f right (reversed) I, CHAV 20.270305 (labial view); g left maxilla with P4-M3, FSL 98227 (palatal view)

Diagnosis Medium-sized soricid (range of L m1-3 = 3.12-3.37) with strongly pigmented teeth; lower dental formula $=1.3 .1 .3$ with two-rooted p4. Falciform, bicuspulate lower incisor; lower molars with the distolabial crest of the protoconid joining the posterolabial cingulum and $\mathrm{m} 3$ with entoconid. P4 with strongly projecting parastyle, M1 and M2 with a rounded hypocone and M3 reduced posteriorly.

Differential diagnosis C. burkarti is ascribed to the genus Carposorex because, during the European Early Miocene, it is the unique genus with the disto-labial crest of the protoconid joining the distal cingulid. It differs from Carposorex sylviae by its smaller size, pigmented teeth and less roughly wrinkled enamel, in the presence of three 
Table 4 Measurements of the lower and upper dentitions of Carposorex from Chavroches (in $\mathrm{mm}$ )

\begin{tabular}{|c|c|c|c|c|c|}
\hline & \multirow[t]{2}{*}{$N$} & \multicolumn{2}{|l|}{$L$} & \multicolumn{2}{|l|}{$W$} \\
\hline & & Range & Mean & Range & Mean \\
\hline p4 & 10 & $0.78-0.95$ & 0.88 & $0.48-0.63$ & 0.57 \\
\hline $\mathrm{m} 1$ & $17 / 16$ & $1.23-1.43$ & 1.30 & $0.73-0.90$ & 0.80 \\
\hline $\mathrm{m} 2$ & 16 & $1.14-1.35$ & 1.24 & $0.74-0.90$ & 0.81 \\
\hline $\mathrm{m} 3$ & 9 & $0.90-1.10$ & 1.00 & $0.56-0.87$ & 0.67 \\
\hline p4-m3 & 3 & $3.95-4.40$ & 4.13 & & \\
\hline $\mathrm{m} 1-3$ & 6 & $3.12-3.37$ & 3.28 & & \\
\hline P4 & 2 & $1.46-1.48$ & 1.47 & $1.25-1.32$ & 1.29 \\
\hline M1 & 6 & $1.10-1.36$ & 1.25 & $1.32-1.65$ & 1.52 \\
\hline M2 & 2 & & 1.15 & & 1.50 \\
\hline M3 & 1 & & 0.67 & & 1.17 \\
\hline P4-M3 & 1 & & 4.20 & & \\
\hline M1-3 & 1 & & 2.91 & & \\
\hline
\end{tabular}

lower antemolars instead of two; 4 shows two well-separated roots and two subequal posterior crests instead of only the postero-labial crest developed in C. sylviae and the molar talonids are not reduced.

Paratypes left Md with ascending ramus and condyle (ML CHAV 20.270301); left i (ML CHAV 20.270302); left fragment Mmd with i-m2, except a 2 (ML CHAV 20.270303); left Mx with P4-M3 (ML CHAV 20.270304); right I (ML CHAV 20.270305); fragment Mx, isolated upper teeth (ML CHAV 20.270310-20.270314); fragment Md with teeth (ML CHAV 20.270315-20.270320).

\section{Measurements Table 4}

Description of the holotype The horizontal branch of the type-mandible (Fig. 3c) gets thicker from front to posterior part; the ascending ramus is high (height of the coronoid process $=3.67$ ) and its anterior margin is less oblique than the posterior one, with a rounded coronoid spicule and an external temporal fossa slightly oblique. The mental foramen is located low under the anterior root of $\mathrm{p} 4$.

The p4 has two well-separated roots; its shape is elongated with two divergent posterior crests sub-equal in length; it also displays a well-developed cingulum with a minute median postero-tubercle. The labial border of $\mathrm{p} 4$ is more rounded and longer than the lingual one.

The molars are characterised by a protoconid-distolabial crest joining the labial cingulum; the cingula are well marked and present also lingually; $\mathrm{m} 2$ is generally a little smaller than $\mathrm{m} 1$; the entoconids and the curved entocristids are well developed and the hypolophids end before the lingual border. $\mathrm{m} 3$ possesses a well-developed and rectangular talonid with a minute entoconid.

Description of referred material No mandibular condyles are well preserved and only their shape can be observed: they are nearly triangular with rounded angles (Fig. 3a2). The mandibular foramen is also low under the internal temporal fossa, the posterior and upper angle of which are rounded (Fig. 3a1).

The falciform and bicuspulate lower incisor possesses a strong posterior cingulum; the axes between its crown and its root form an obtuse angle. There are three one-rooted antemolars, the a2 being not preserved. a1 rests on the posterior part of the incisor and possesses two divergent crests, the lingual one being longer; a3 displays a relatively large root, aligned with the other roots and a minute crown hidden under the anterior part of $\mathrm{p} 4$. On the molars, the distolabial crest of the protoconid is more or less visible-and sometimes disappears in $\mathrm{m} 2$ and/or $\mathrm{m} 3$ (Fig. 3c, d).

The upper incisor is large with a strong posterolabial cingulum; the heel consists of an acute labial tubercle and a lingual ridge. The number of upper antemolars is unknown. P4 has a strong paracone delimited by a rectilinear labial border and a strongly projecting parastyle with short parastylar crest. P4 is concave anteriorly and markedly concave on posterior side; its lingual border shows an enlarged cingulum without hypocone.

Upper molars-hitherto unknown in Carposorex-are massive, slighty wider than long; their hypocone protrudes strongly lingually and continues in a marked postero-cingulum reaching the metastyle; the anterior arm of the protocone continues under the paracone of M1 and M2. M1 is slightly larger than M2. M3 is proportionally wide with a transversally elongated metaloph that constitutes the posterior edge; the metacone is not visible.

The maxilla shows a well-developed jugal apophysis; in labial view, the infra-orbital foramen ends above the midpoint of M1 and its posterior margin is perpendicular to the base of the maxilla; the bridge over the infraorbital canal ends posteriorly above the paracone of M2; the lacrimal foramen is large and high.

Discussion Due particularly to differences not only in size but also to different evolutionary level, C. burkarti seems, at first sight, not very close to $C$. sylviae. But Crochet (1975) ascribed to this genus some smaller isolated teeth from Paulhiac (MN1) and La Brète (MN2); the dental formula of these two earlier Carposorex sp. is unknown. However, the minute a3 present in Chavroches is so tiny that its disappearance seems a likely evolutionary trend of Carposorex and moreover, considering a size increase for the genus-as demonstrated by the locality Stubersheim 3 (MN3, Ziegler 1989: $\mathrm{m} 1=1.72 \times 1.00$ vs. $1.56 \times 1.01$ in the earlier type-locality Laugnac)—all these forms could belong to a same evolutionary lineage. Moreover, the Early Miocene locality G-sup yielded a maxilla and a lower incisor that show all the characteristics of Carposorex but are smaller in size (see below). 
Teeth with the disto-labial crest of the protoconid joining the labial cingulum are known in the Oligocene of Europe as soon as the beginning of the Oligocene (MP 21) in Srinitium caeruleum (this characteristic is not seen however in the type-species $S$. marteli) and in the late Oligocene Ulmensia ehrensteinensis and $U$. antecedens (Ziegler 1989, 1998a), but these forms are massive with wide cingulids and, at the end of the Oligocene, $U$. ehrensteinensis displays also some differences in the upper teeth (hypocone absent in M1-2, M3 with visible metacone) and is much larger so that an eventual relationship with Carposorex would imply an abrupt decrease in size.

In the Upper Oligocene of Mongolia, Ziegler et al. (2007) described a new genus and species, Tavoonyia altaica, which displays many similarities with $C$. burkarti. Common characteristics are m1-2 with the distolabial crest of the protoconid, three antemolars, p4 with two divergent sub-equal crests, and M1 with rounded hypocone. Some differences exist, however: Tavoonyia size seems to be a little smaller and p4 seems to be shorter; the hypoconid flange of M1 is less expanded so that the protocone protrudes lingually and, moreover, an incomplete mesoloph is present. But many usual diagnostic features of soricids are unknown for Tavoonyia (such as the lower incisor, pattern of $\mathrm{m} 3, \mathrm{P} 4$, and M2-3) and we consequently prefer to ascribe the Chavroches material to Carposorex as archaic member of the $C$. sylviae lineage.

Relationships between the Asian group Tavoonyia, Aralosorex Lopatin, 2004 (this genus with apparently not procumbent p4) and the European groups comprising, on one side, the Oligocene genera Srinitium and Ulmensia and, later, the Miocene Carposorex seems to be evident, but these relationships can not be determined more accurately, according to the present available fossil data.

\section{Carposorex aff. burkarti}

Figure $3 \mathrm{~g}$

Material and measurements Gannat: G-sup: FSL 98227, left $\mathrm{Mx}$ with $\mathrm{P} 4-\mathrm{M} 3 \quad(\mathrm{P} 4-\mathrm{M} 3=3.80, \mathrm{M} 1-3=2.60$, $\mathrm{P} 4=1.16 \times 1.49, \quad \mathrm{M} 1=1.06 \times 1.39, \quad \mathrm{M} 2=1.06 \times$ $1.39, \mathrm{M} 3=0.62 \times 1.15) ;$ FSL 98228, left I $(1.49 \times 0.65)$; FSL 98229, right $\mathrm{m} 1(1.24 \times 0.75 \times 0.75)$; FSL 98230, right $\mathrm{m} 1 \quad(1.20 \times 0.70 \times 0.72) ;$ FSL 98231, left $\mathrm{m} 2$ $(1.14 \times 0.70 \times 0.72)$. G-81: one damaged lower incisor.

Discussion The maxilla with P4-M3, even if smaller in size, compares morphologically so well with the material from Chavroches that it is ascribed to $C$. burkarti with some differences, however. P4 displays a faint swelling at the beginning of the hypoconal flange. M1 and M2 are more compressed antero-posteriorly; the posterior arm of the protocone bifurcates in a faint metaloph (present in Tavoonyia) and a posterior crest directed toward the rounded hypocone; these two crests have disappeared in the Chavroches specimens; the M3 metacone is still visible in the posterior crest. The lower incisor is identical to those of Chavroches.

This material indicates that Carposorex is present in Limagne as soon as the beginning of the Miocene and that it could be also an Early Miocene immigrant.

Genus Soricella Doben-Florin, 1964

Type species Soricella discrepans Doben-Florin, 1964 Type locality Wintershof-West (Germany), Early Miocene (MN3)

Soricella cf. discrepans Doben-Florin, 1964

Material and measurements FSL 4423 coll. Viret, left mandible from Chavroches with $\mathrm{m} 1, \mathrm{~m} 2$ and the alveoli of $\mathrm{i}$, a1, a2, two-rooted $\mathrm{p} 4$ and $\mathrm{m} 3$, ascending ramus without condyle $(\mathrm{H}$ coronoid process $=5,1)$

Description The molars of the mandible are proportionally large $(\mathrm{m} 1=1.53 \times 0.89, \mathrm{~m} 2=1.38 \times 0.89$ ?, m1-3 (aveolar length $=3.86$ ) and they display a characteristic morphology: the hypolophid joins directly the entoconid and no distolabial crest of the protoconid connects to the massive distolabial cingulid. This mandible comes from old collections, and as several quarries were worked in Chavroches, its precise location-and consequently its precise level-is unknown.

No other material showing the typical hypolophidentoconid joint has been found in the recent excavations from Chavroches, but in the lower levels of the Montaigule-Blin quarry, one isolated tooth (left m2?, FSL $98235=1.36 \times 0.95)$ shows also this characteristic and is ascribed to Soricella.

The figures of Chavroches and Montaigu (lower levels) correspond to the values given for the population from Ulm/Westtangente ascribed by Ziegler (1989) to $S$. cf. discrepans because of their little smaller size.

Genus Oligosorex Kretzoi, 1959

Type species Sorex antiquus Pomel, 1853

Type locality Saint-Gérand-le-Puy (France, Allier), Early Miocene (MN2a)

Oligosorex aff. antiquus (Pomel 1853)

Figure $4 \mathrm{c}$, e

Material and measurements Table 5; Saulcet: NMB Sau 4533, right Mx with P4-M3; NMB Sau 4481, right Mmd with $\mathrm{m} 1-\mathrm{m} 3(\mathrm{~m} 1-3=3.25)$; other NMB $\mathrm{Mx}$ and $\mathrm{Md}$ not studied here; ML SG 841, left Md with m1-3 (m1-3 = 3.26); ML SG 842, left Md with I and $\mathrm{m} 2$ (figured in Hugueney 1974). Chavroches: ML CHAV 20. 270308, right Md with $\mathrm{p} 4-\mathrm{m} 1$, ascending ramus and condyle. 

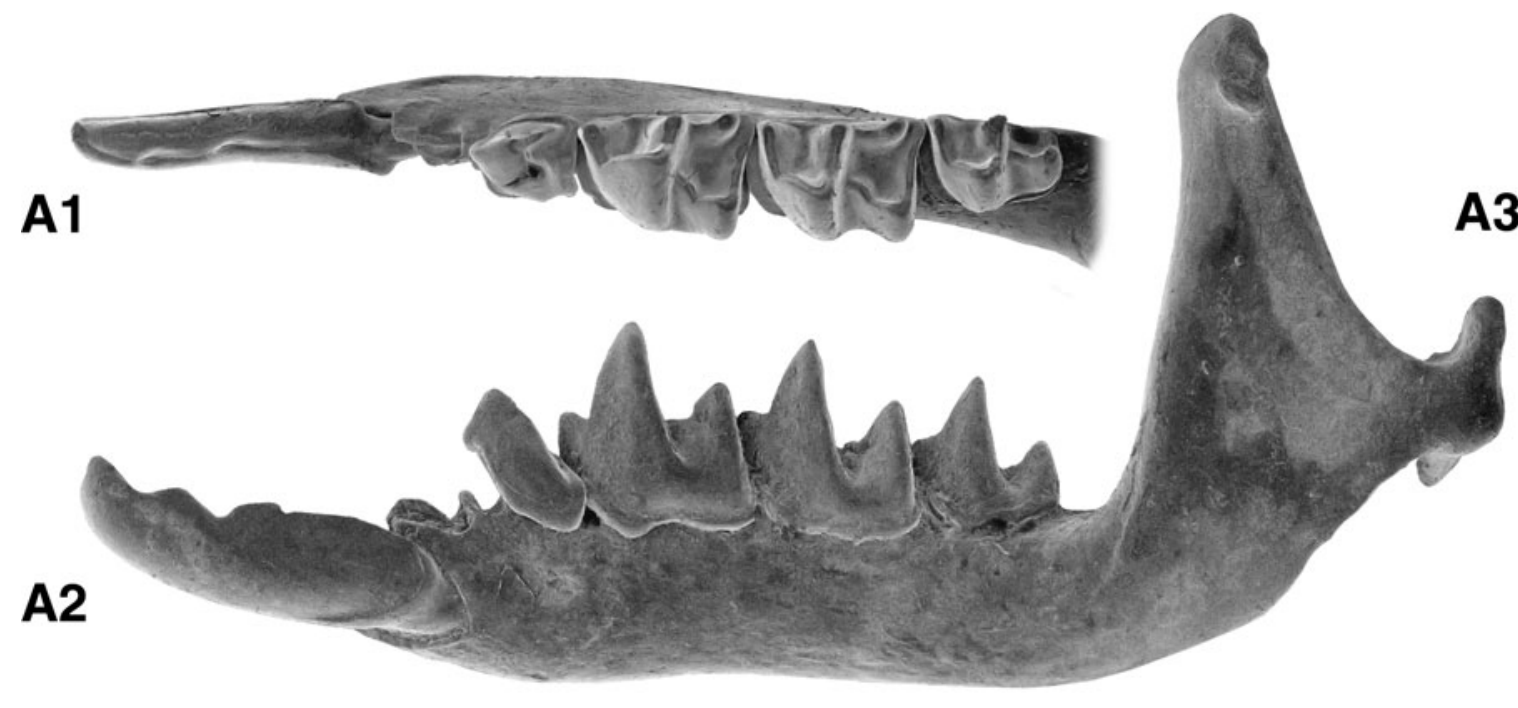

A3
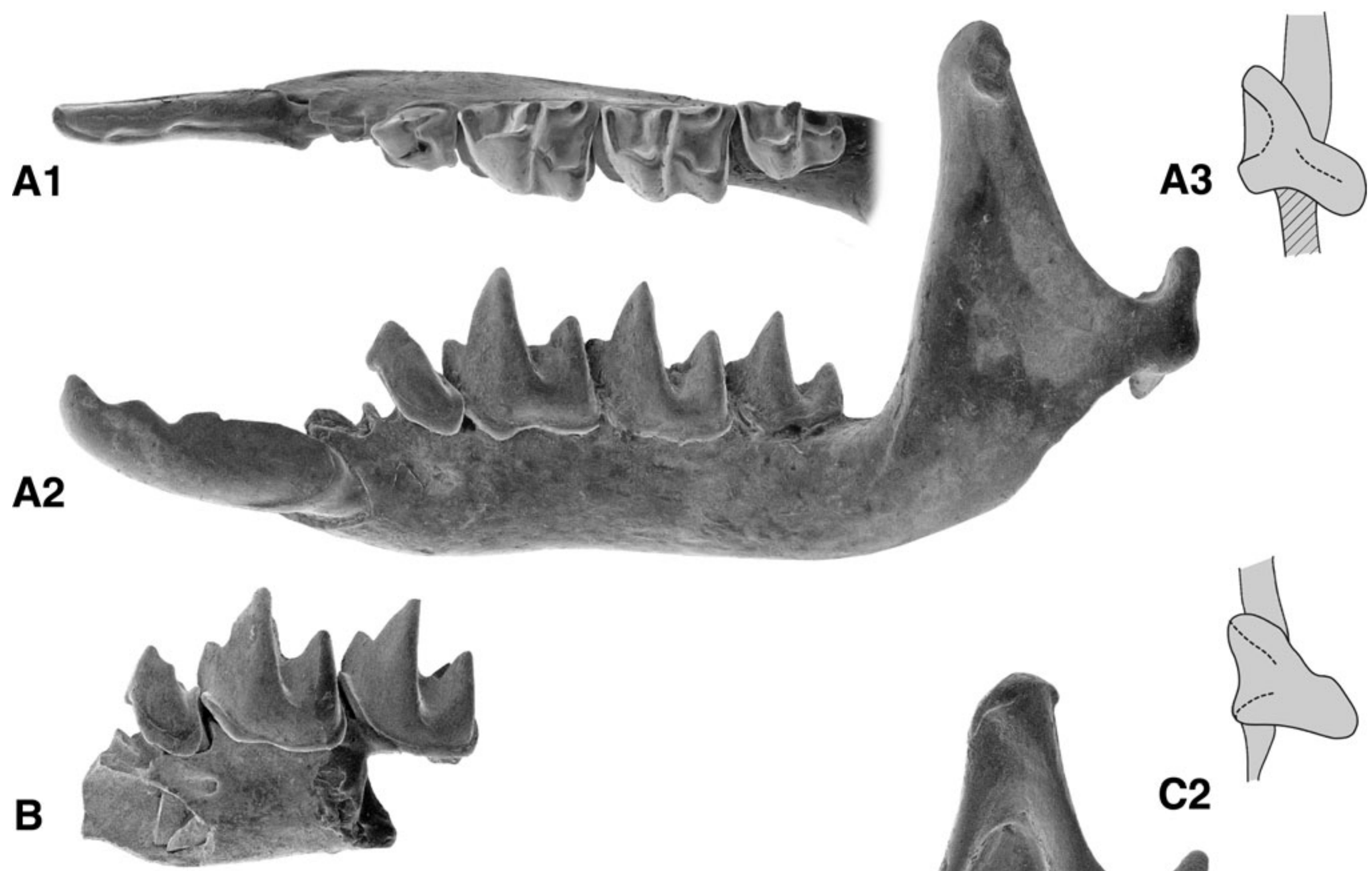

$1 \mathrm{~mm}$

\section{C1}
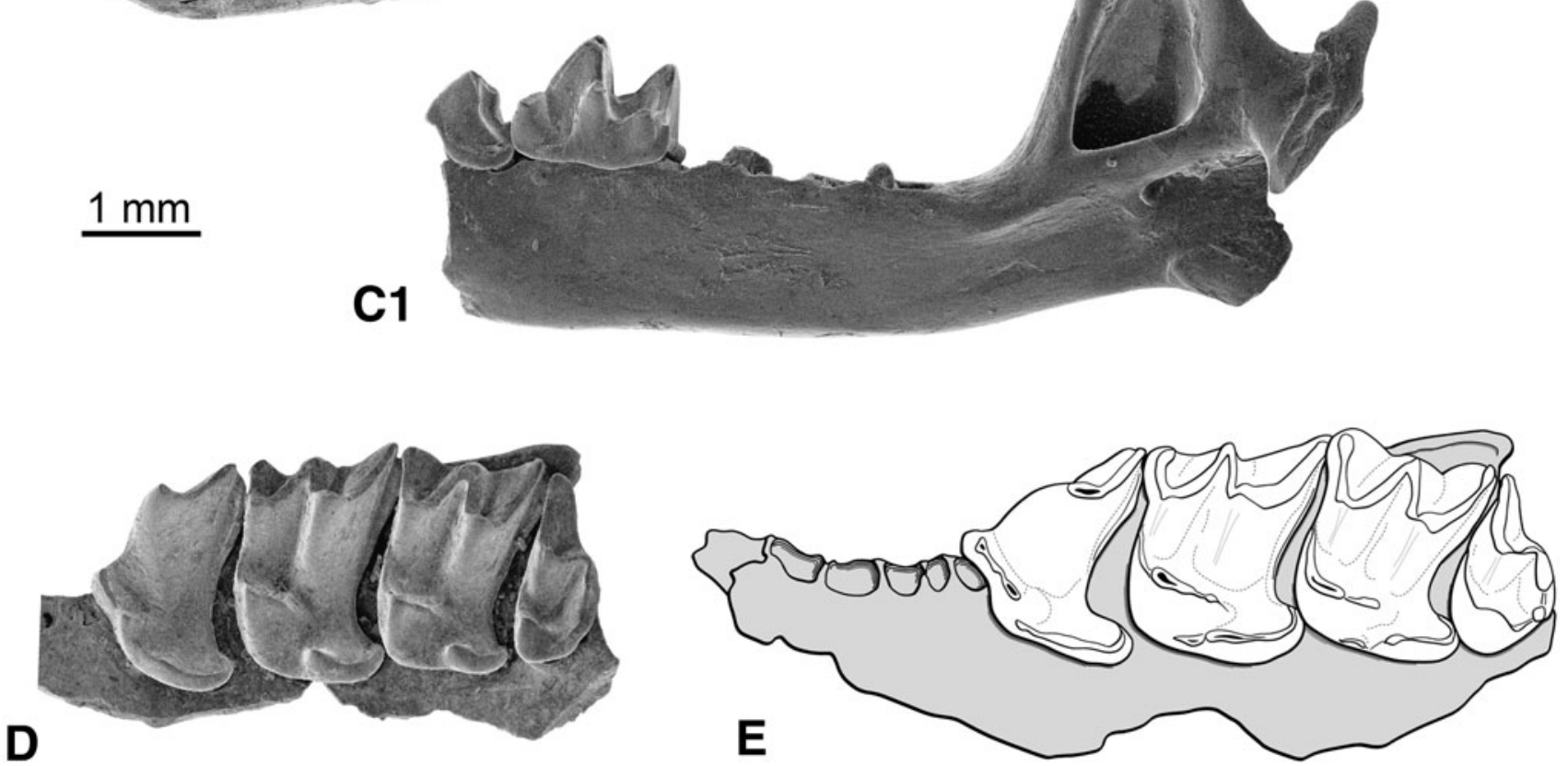

Fig. 4 Crocidosoricinae indet. from Chavroches (a, d), and from Gannat-sommet (b), Oligosorex aff. antiquus from Chavroches (c) and from Saulcet (e): a left mandible with I and p4-m3, ML CHAV 20.270306 [a1 occlusal view, a2 labial view, a3 sketch of condyle in caudal view, b left mandible with p4-m2, FSL 98226

Description Oligosorex is a genus often reported from the Early Miocene and even earlier from the Late Oligocene; the characteristics of its lower teeth are summarized by Engesser and Storch (2008): lower dental formula with

(labial view)]; c right mandible with p4-m1, ML CHAV 20.270308 (c1 lingual view, c2 sketch of condyle, reversed caudal view); d left maxilla with P4-M3, ML CHAV 20.270307 (palatal view); e right maxilla with P4-M3 (reversed), NMB 4533, (palatal view)

three single-rooted antemolars, the a 3 being minute in front of the double-rooted $\mathrm{p} 4$; hypoflexids of $\mathrm{m} 1$ and $\mathrm{m} 2$ open well above the ectocingulid; no protoconid-disto-labial edge confluent with postero-ectocingulid; ectocingulid 
Table 5 Measurements of the lower and upper dentitions of Oligosorex aff. antiquus from Saulcet (Sau) and Chavroches (Chav) (in $\mathrm{mm})$

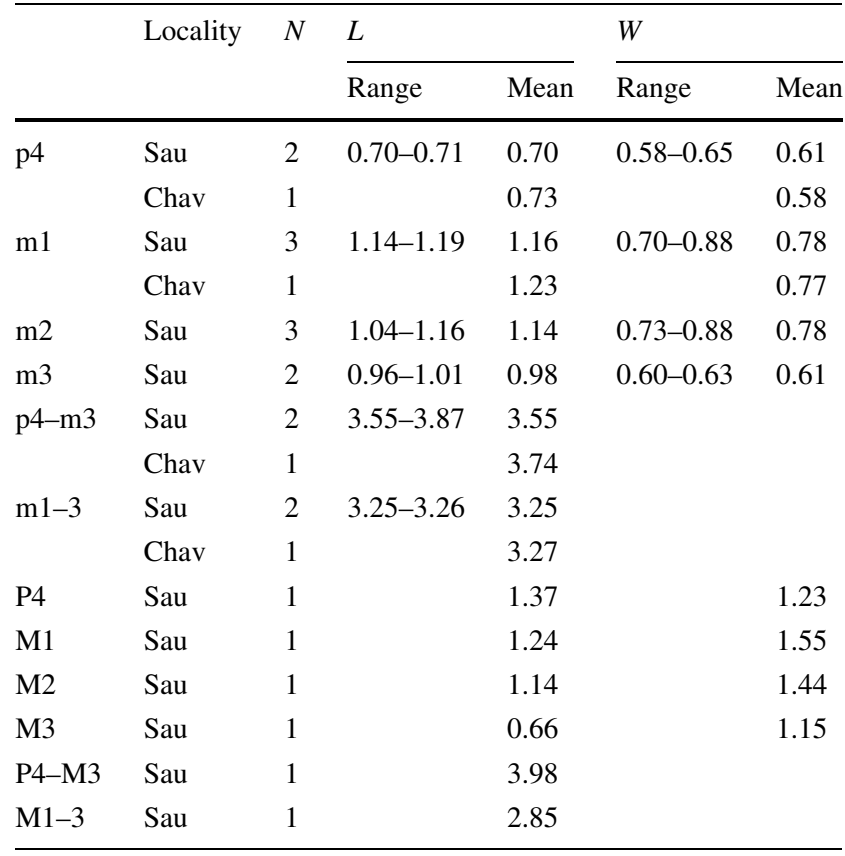

irregular, especially thin and often interrupted below the protoconid, precingulid well developed; the cusps of the lower molars are high and sharp, the trigonid basin is deep and very open, especially in $\mathrm{m} 1$; slender bicuspulate $i$.

Maxillary teeth are massive, $\mathrm{P} 4$ with moderate projecting anterocone and without hypocone, M1-M2 with moderate posterior emargination, faintly developed hypocone and without lingual cingulum - a short cingulum is, however, often present in front of the hypocone. M3 relatively large, metastyle well marked and more or less independant from the posterior border of the tooth.

Discussion The material from the Early Miocene of Limagne is morphologically similar to $O$. antiquus but of smaller size than the typical $O$. antiquus and its size corresponds better to that of $O$. thauensis (Crochet 1975) from Bouzigues (MN2b). The $O$. aff. antiquus mandible from Saulcet (Hugueney 1974; Fig. $1 ; \mathrm{m} 1-3=3.26$ ) is very similar to the type-mandible except for being smaller. In Chavroches, a slightly larger right mandible (Fig. 4d) shows a triangular ascending ramus with internal temporal fossa similar to that of the type-mandible (Hugueney and Maridet 2011; Fig. 2c); the height of the coronoid process is 3.31. The shape of the condyle is also similar with its horizontally enlarged base and its upper part slightlly excavated lingually

The maxilla from Saulcet has a size similar to that of $O$. thauensis, but its premolar and molars seem a little more emarginated posteriorly and the emargination is more lingual; the M3 shows a well-individualised metacone as in $O$. antiquus (the $\mathrm{M} 3$ of $O$. thauensis is not figured but is described as very reduced).

The lower levels of Montaigu-le-Blin quarry often yield isolated soricid material (particularly more or less fragmentary mandibles); even if they are a little smaller than those of the upper levels - the locus-typicus of the typethey are generally ascribed to $O$. antiquus (Hugueney 1974), but some of them could as well pertain to the genus Clapasorex and only very complete and unworn material can be determinated with certainty.

Some German fossils from Upper Oligocene or Early Miocene (Ziegler 1989; Engesser and Storch 2008) have been ascribed to $O$. thauensis in view of their similar size. But relationships between $O$. antiquus and $O$. thauensis are completely unknown and, in the present state of our knowledge, we think it impossible to choose between the two species. In our opinion, however, the Limagne material is more likely a primitive representative of the $O$. antiquus lineage, in view of its similar geographic location.

Crocidosoricinae gen. and sp. indet.

Figure $4 a, b, d$

Material and measurements Chavroches: ML CHAV 20.270306, left Mmd with i, p4, m1-3, ascending ramus and condyle $(\mathrm{L}$ p4 $-\mathrm{m} 3=4.02 ; \mathrm{L} \mathrm{m} 1-3=3.30 ; \mathrm{i}=2.45 \times$ $0.59 ; \mathrm{p} 4=0.79 \times 0.59 ; \mathrm{m} 1=1.22 \times 0.81 ; \mathrm{m} 2=1.21 \times$ $0.82 ; \mathrm{m} 3=1.03 \times 0.62 ; \mathrm{H}$ ascending ramus $=3.49) ; \mathrm{ML}$ CHAV 20.270309, left Mmd with p4-m3 (p4-m3 = 4.01; $\mathrm{m} 1-3=3.34 ; \quad \mathrm{p} 4=0.79 \times 0.57 ; \quad \mathrm{m} 1=1.24 \times 0.81 ;$ $\mathrm{m} 2=1.23 \times 0.80 ; \quad \mathrm{m} 3=0.97 \times 0.63) ; \quad$ ML $\quad$ CHAV 20.270307, left Mx with P4-M3 (L P4-M3 = 3.74; L $\mathrm{M} 1-3=2.70 ; \quad \mathrm{P} 4=1.31 \times 1.17 ; \quad \mathrm{M} 1=1.16 \times 1.52 ;$ $\mathrm{M} 2=1.04 \times 1.41 ; \mathrm{M} 3=0.62 \times 1.21)$.

G-som: FSL 98226, left fragmentary mandible with anterior alveoli and $\mathrm{p} 4-\mathrm{m} 2(\mathrm{~L}$ p4-m2 $=2.82 ; \mathrm{p} 4=$ $0.70 \times 0.63 ; \mathrm{m} 1=1.18 \times 0.82 ; \mathrm{m} 2=1.17 \times 0.78)$.

Discussion The mandible from Chavroches with i, p4-m3, ascending ramus and condyle is roughly of the same size as Oligosorex of Chavroches, the teeth being not very different except the bicuspulate $i$ that seems a little more curved; the lower dental formula is 1.3.1.3, with the minute root of a3 lingual of the anterior root of the V-crested p4; the mental foramen is under the posterior part of $\mathrm{p} 4$. The ascending ramus is nevertheless different, its coronoid process is much more compressed antero-posteriorly and higher (coronoidal $\mathrm{H}=3.49$ ) with a double coronoid spicule and the external temporal fossa enclosed between the posterior edge and a long parallel anterior crest; the condyle is placed above the tooth-row, and the condyle base is not horizontal but obliquely directed lingually (Fig. 4a1-a3). The internal temporal fossa is large and triangular; its base is parallel to the upper border of the 
horizontal ramus with the mandibular foramen posterior to the middle of the fossa. Teeth are pigmented.

A left maxilla (Fig. 4d) of corresponding size is ascribed to the same form; the number of antemolars is unknown. P4 shows a parastyle not projecting anterolabially, a parastylar crest ascending to the paracone and without hypocone. M1-2 are a little compressed antero-posteriorly, with lingual emargination of posterior border and small but marked hypocone but without lingual cingulum. M3 is wide with metacone fused in a crest constituting the posterior border of the tooth.

This form shows a mixture of Oligosorex and Clapasorex characteristics: parastylar crest of $\mathrm{P} 4$, antero-posteriorly compressed molars, width of M3 proportionally large and metacone disappearing in the posterior crest, lower molars with thin cingula, relatively long $\mathrm{m} 3$ remind of Clapasorex (at least those of the Early Miocene levels) but
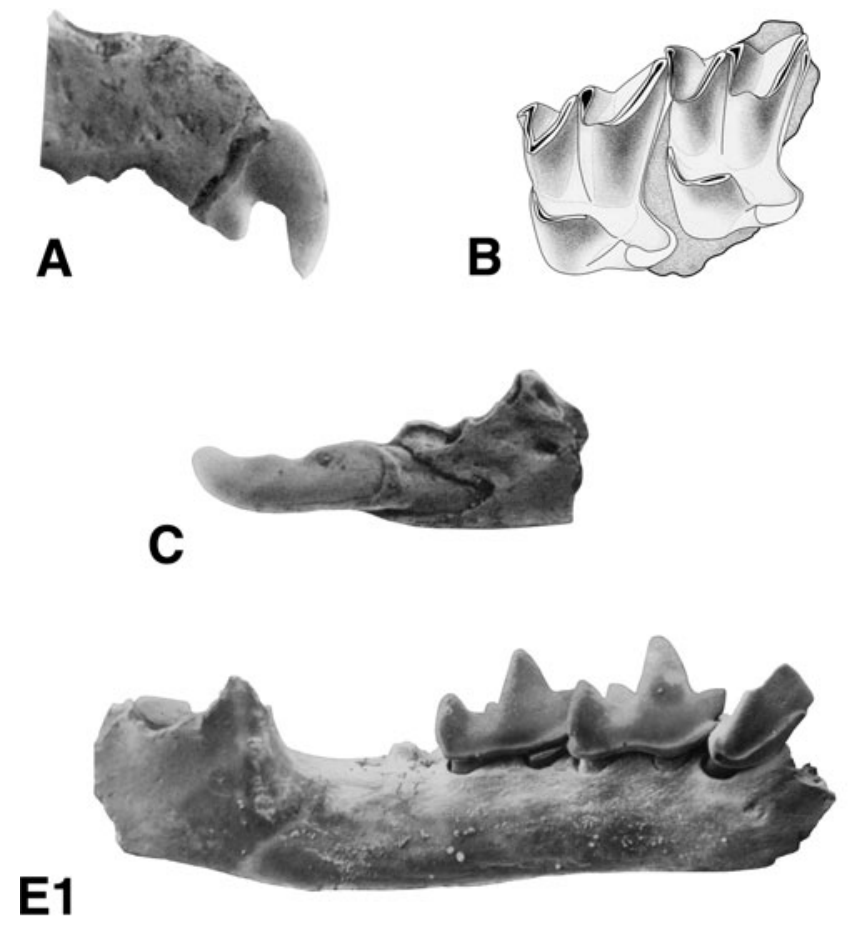

E1

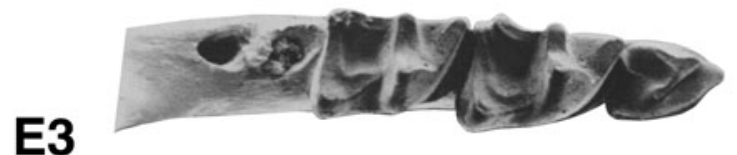

Fig. 5 Miosorex desnoyersianus (Lartet, 1851) from Vieux-Collonges: a right maxilla with I and antemolars alveoli, FSL66695 (labial view); b left maxilla with M1 and M2, FSL 66672 (occlusal view); c left mandibular fragment with i and antemolars alveoli, FSL 66694 absence of lingual cingulum in M1-2, larger size remind of Oligosorex. For the mandible, i, coronoid process and condylar process differ from the other species known in the Early Miocene. The material, even if well-preserved, is insufficient to ascribe this form to a known genus or to describe a new taxon.

In Gannat-sommet, the fragmentary mandible shows the same characteristics as in Chavroches but the mental foramen is a little more posterior; $\mathrm{p} 4$ seems a little more compressed antero-posteriorly, $\mathrm{m} 1$ and $\mathrm{m} 2$ display massive and rectangular teeth, but the cingulum of $\mathrm{m} 1$ is almost interrupted under protoconid as in Oligosorex; teeth are pigmented.

Genus Miosorex Kretzoi, 1959

Type species Sorex grivensis Deperet 1892

Type locality La Grive (France, Isère), Middle Miocene

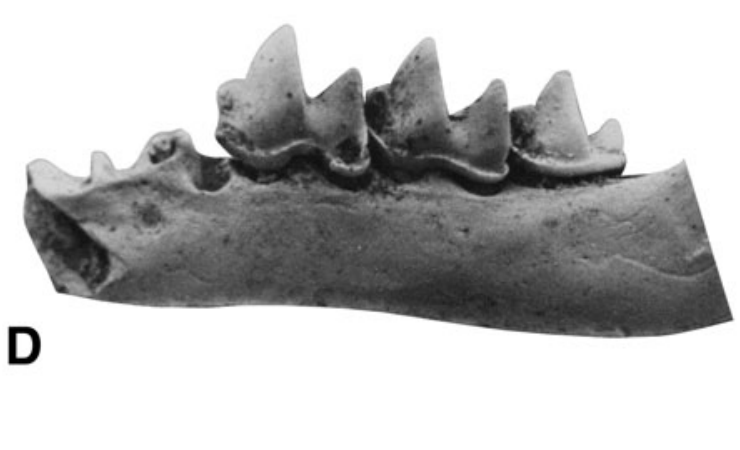

E2
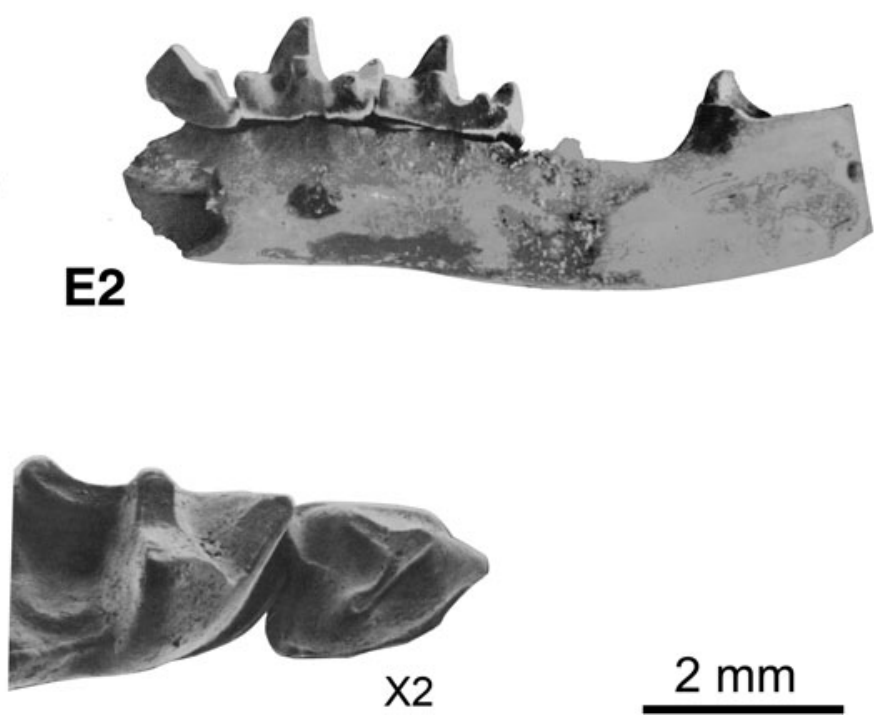

$2 \mathrm{~mm}$

(labial view); d left mandible with m1-m3, FSL 66678 (labial view); e right mandible with $\mathrm{p} 4-\mathrm{m} 2$, MLMC 415, type specimen of Sorex collongensis (Mein 1958) (e1 labial view, e2 lingual view, e3 occlusal view plus double-sized close-up of p4) 
Miosorex desnoyersianus Lartet, 1851

Figure 5a-e

Type locality Sansan (France, Gers), early Middle Miocene (MN6)

Material Vieux-Collonges: FSL 66667-FSL 66697, including two maxillae, a dozen mandibles with preserved ascending ramus and numerous isolated teeth.

Measurements L m1-m3: Mean $=3.13$, Min $=2.91$, $\operatorname{Max}=3.27$.

Description In Vieux-Collonges, represented by abundant material including many fragments, there is a medium-sized soricid with two antemolars and a biradiculate $\mathrm{p} 4$; the anterior root of this tooth is smaller than the posterior one. The lower molars $\mathrm{m} 1$ and $\mathrm{m} 2$ are the same size and they are preceded by four alveoli; the two last belonging to $\mathrm{p} 4$, there are only two antemolars. In the upper teeth, M1 and M2, the posterior arm of the protocone descends towards the hypocone without any connection.

Discussion Miosorex desnoyersianus is only present in Vieux-Collonges and represented by an abundant material including hundreds of fragments. This material was first described by Mein (1958), as Sorex collongensis n. sp., the material from Sansan was unknown at the time. Later
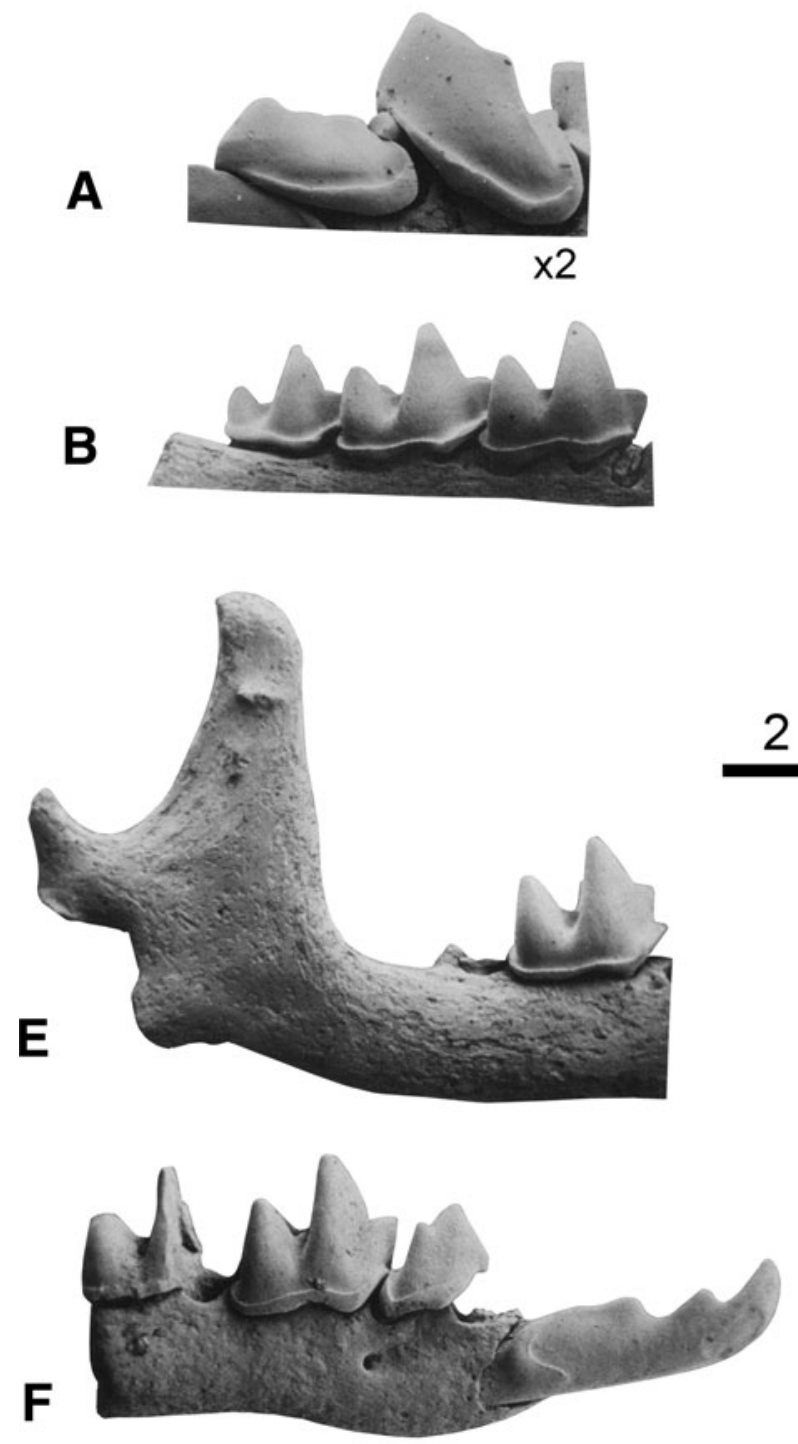

Fig. 6 Miosorex grivensis Deperet, 1892 from La Grive L7 (a) and M (b-g): a left antemolar a1 with vestigial a2 and p4, FSL 66726a (double-sized close-up in labial view); b right mandible with m1-m3, FSL 66748 (labial view); c left maxilla with I-M1, FSL 66732 (c1 labial view, c2 palatal view); d left maxilla with P4-M2, FSL 66736

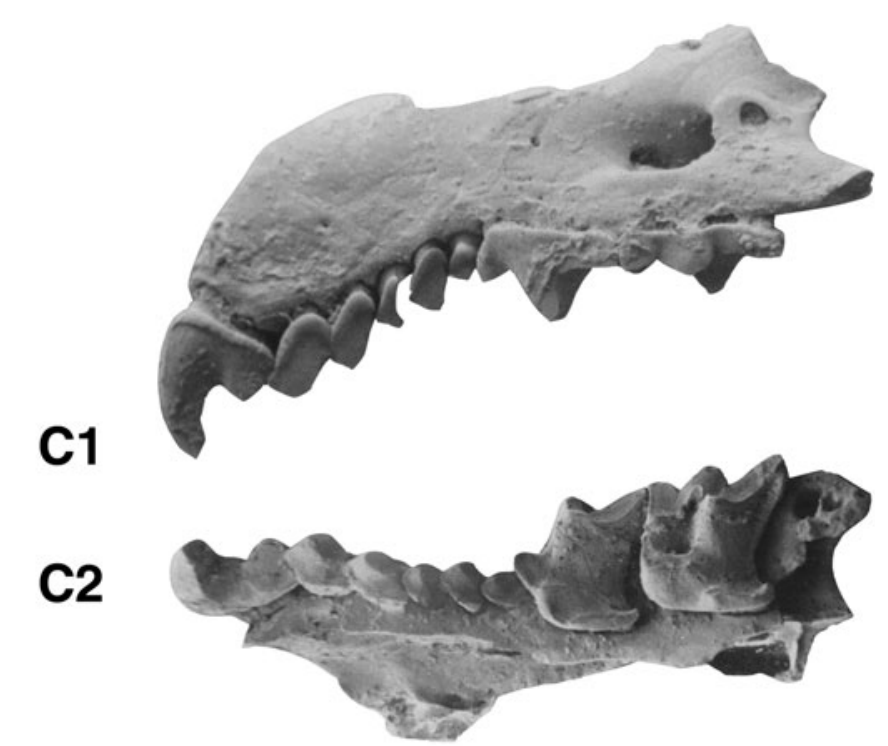

\section{$2 \mathrm{~mm}$}

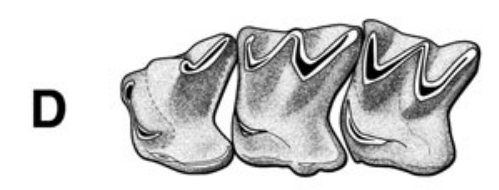

G1

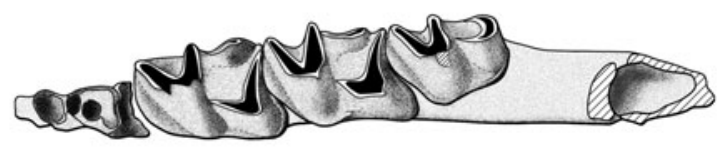

G2

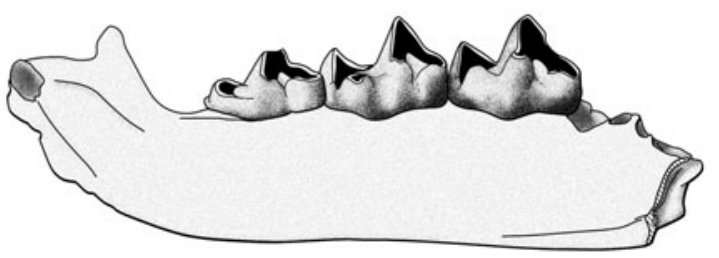

(occlusal view); e right mandible with ascending ramus, FSL 66750 (labial view); f right mandible with i and p4-m2, FSL 66749 (labial view); g left mandible with m1-m3, FSL 66748 (g1 occlusal view, g2 lingual view) 
Baudelot (1972) proposed, in her Ph.D. thesis on Sansan material, attributing $S$. desnoyersianus to the genus Miosorex Kretzoi, 1959. No specific features can be used to separate $S$. collongensis from M. desnoyersianus, so we recognize here the synonymy of the Vieux-Collonges $S$. collongensis with $M$. desnoyersianus. This species has been described in Engesser (2009) with an emended diagnosis.

Miosorex grivensis Deperet, 1892

Figure $6 \mathrm{a}-\mathrm{g}$

Material La Grive L3: FSL 66698-66702, including one maxilla, five mandibles, and numerous isolated teeth. La Grive L5: FSL 66703-66709 including one I, one P4, one mandible, one $\mathrm{i}$, one $\mathrm{p} 4$, one $\mathrm{m} 1$ and one $\mathrm{m} 2$. La Grive L7: FSL 66710-66731, including maxillae with preserved I, P4, M1, and M2, plus numerous mandibles and isolated molars. La Grive M: from FSL 66732-66756, including maxillae, several isolated upper teeth from I to M3, mandibles with ascending ramus; several isolated lower teeth from $\mathrm{p} 4$ to $\mathrm{m} 3$, also post-cranial elements such as humeri and ulna.

Measurements La Grive M: length m1-m3: average 3.61 minimum length: 3.27- maximal length: 3.91. La Grive L7: length $\mathrm{m} 1-\mathrm{m} 3$ : average 3.74 minimum length: $3.52-$ maximal length: 4.05 .

Description Miosorex grivensis is the most abundant shrew in all the fissures of La Grive. M. grivensis was initially described from La Grive by Deperet (1892), then studied by several authors such as Major (1899) and Viret and Zapfe (1952) who gave precise descriptions of the mandibular ramus and the position of the mental foramen. In the L7 fissure of La Grive, an orange pigmentation can be seen on the tips of the lower incisor and molars; in the other fissures, this colouration is lost. In some specimens, as in La Grive M (MLMC 257), the antemolar A2 is missing; this feature is also seen in La Grive L3. In the aforementioned specimens, only the alveoli of the anterior teeth are preserved and four sockets can be counted: the two last are for $\mathrm{p} 4$, so two antemolars a1and a 2 are present; $\mathrm{a} 2$ is the smaller and a1 the bigger; the mental foramen is located below the anterior socket of $\mathrm{p} 4$.

Discussion Two successive species of Miosorex are found in the aforementioned localities: Miosorex desnoyersianus (Lartet, 1851) and Miosorex grivensis (Deperet, 1892). The two species are mainly differentiated by size. Miosorex desnoyersianus is the smaller. The first occurrence of the genus is known in Germany, MN3 with Miosorex pusilliformis (Doben-Florin, 1964), and the last record is in the Late Miocene of Spain (MN10) with Miosorex grivensis (Van Dam 1997; Ziegler 2003).

Genus Lartetium Ziegler, 1989
Type species Sorex prevostianus Lartet, 1851 Type locality Sansan (France, Gers), early Middle Miocene (MN6)

Remarks on the genus Lartetium The genera Lartetium and Miosorex are closely related Crocidosoricinae co-existing in the localities of La Grive and VieuxCollonges. Despite some common primitive features and a similar size, several morphologic characters distinguish Miosorex from Lartetium. Lartetium possesses three lower antemolars before p4 (often only two for Miosorex as the specimens here studied) and four upper antemolars before P4 (as opposed to five for Miosorex). Furthermore, on the maxilla, the three anterior foramina are large and triangular-shaped for Lartetium, whereas only very small foramina can be seen in Miosorex; in the two genera the anterior part of the maxilla, bearing the antemolars, makes an angle with the posterior part bearing the molariform teeth (including P4); for Lartetium this angle is near $130^{\circ}$, but is about $170^{\circ}$ in Miosorex. In Lartetium the P4 shows a cusp located behind the protocone, which is the hypocone, whereas this cusp is lacking in Miosorex.

Either based on preserved roots or on maxillary sockets, it is possible to compare the number of roots of M1 between the two genera: Miosorex shows three aligned roots on the labial edge, whereas Lartetium possesses only two main labial roots on the same labial edge; however, a third tiny root located behind the first anterolabial root is also present in Lartetium.

Remarks on the different species Viret and Zapfe (1952) described a new species Sorex dehmi from three localities: Vieux-Collonges, Devinska Nova Ves (Neudorf) and La Grive. Ziegler (1989) created a new genus Lartetium for Sorex prevostianum Lartet, 1851 with Sansan as the type locality and referred Sorex dehmi from Vieux-Collonges and La Grive as Lartetium dehmi, Vieux-Collonges being the type locality. Lartetium dehmi is the most abundant shrew in Vieux-Collonges and seems, from our point of view, to display significant morphological differences with the specimens from Devinska Nova Ves. Further comparisons including more specimens from the Slovakian locality will be necessary to confirm whether the two populations can be ascribed to the same species.

In contrast, the genus is very rare in La Grive localities where Mein and Ginsburg (2002) described a new species under the name of Lartetium ziegleri.

Lartetium dehmi Viret and Zapfe, 1952

Figure $7 \mathrm{a}-\mathrm{g}$

Type locality Vieux-Collonges (France, Rhône), late Early Miocene (MN5) 

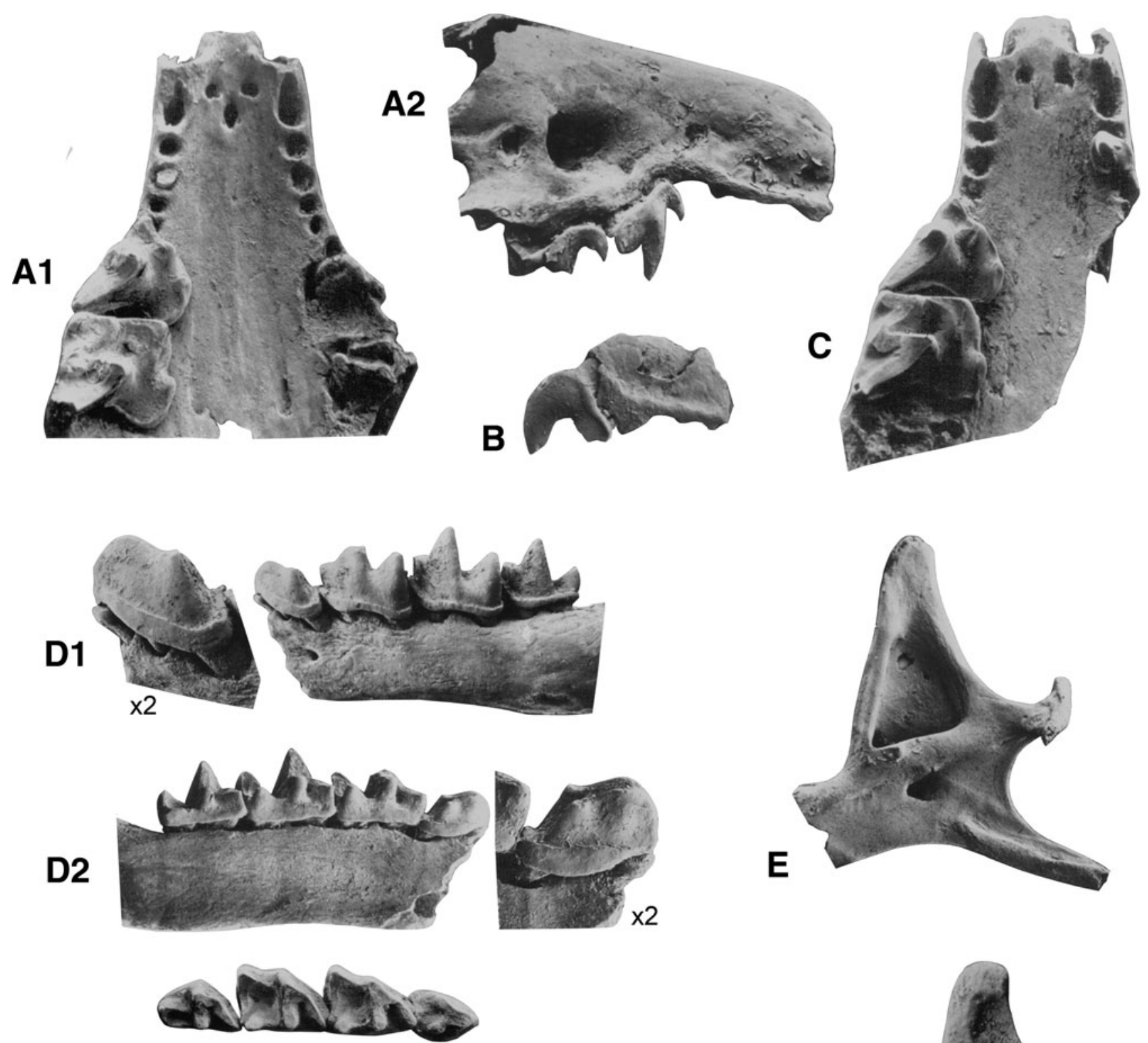

D3
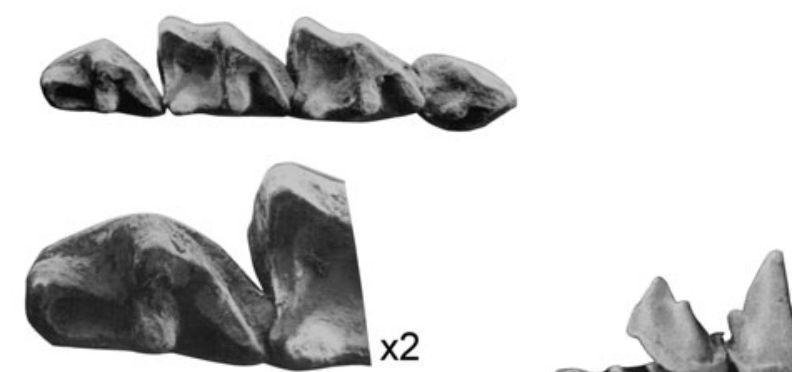

$x 2$
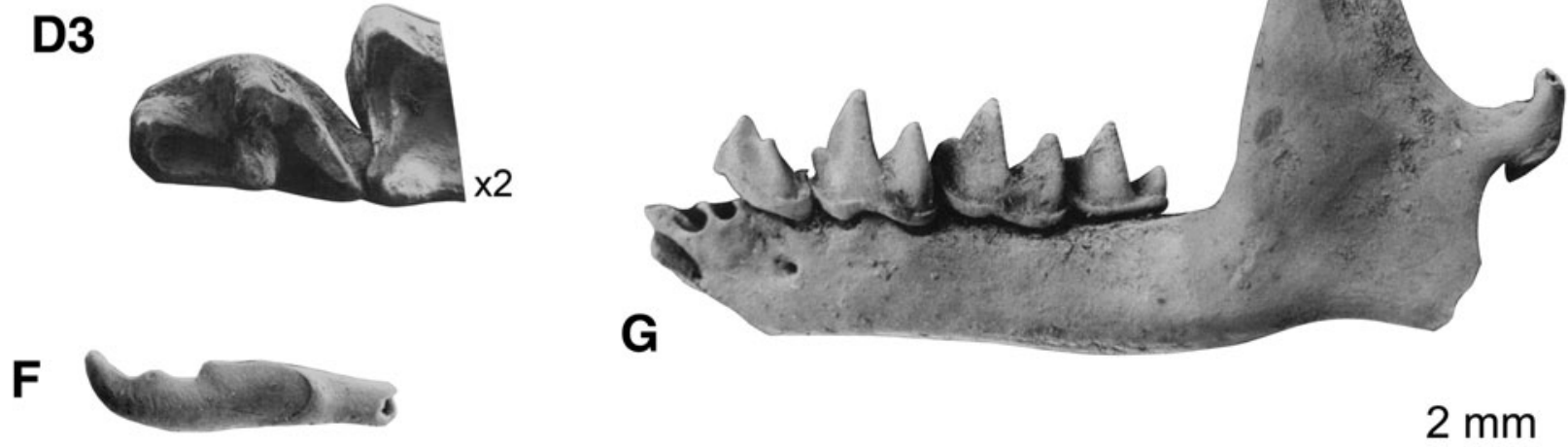

Fig. 7 Lartetium dehmi (Viret and Zapfe 1952) from Vieux-Collonges: a Partial skull with left P4-M1 and five A alveoli, FSL 65716 (a1 palatal view, a2 right lateral view); b Partial left maxilla with incisor and A alveoli, FSL 66757 (left lateral view); c Partial skull with left P4-M1 and alveoli, FSL 65718 (palatal view); d left mandible with p4-m3, MLMC 429 (d1 labial view plus double-sized close-up of p4, d2 lingual view plus double-sized close-up of p4, d3 occlusal view plus double-sized close-up of $\mathrm{m} 3$ ); e right ascending ramus, FSL 66767b (lingual view); f left i, FSL 66775 (labial view); g left mandible with $\mathrm{p} 4-\mathrm{m} 3$ and ascending ramus, FSL 66763 (labial view) 
Table 6 Measurements of Lartetium dehmi mandibles from VieuxCollonges (in mm)

\begin{tabular}{|c|c|c|c|c|c|c|c|}
\hline & \multirow[t]{2}{*}{$N$} & \multicolumn{2}{|l|}{$L$} & \multicolumn{2}{|l|}{$W$} & \multicolumn{2}{|l|}{$H / \mathrm{m} 2$} \\
\hline & & Range & Mean & Range & Mean & Range & Mean \\
\hline $\mathrm{p} 4-\mathrm{m} 3$ & 20 & $4.52-4.90$ & 4.68 & - & - & - & - \\
\hline $\mathrm{m} 1-3$ & 48 & $3.61-4.00$ & 3.75 & - & & - & - \\
\hline $\mathrm{m} 1$ & 47 & $1.32-1.50$ & 1.41 & $0.92-1.07$ & 1.01 & - & - \\
\hline $\mathrm{m} 2$ & 40 & $1.37-1.54$ & 1.46 & $0.93-1.04$ & 0.98 & - & - \\
\hline $\mathrm{m} 3$ & $36 / 35$ & $1.09-1.26$ & 1.18 & $0.65-0.76$ & 0.70 & - & - \\
\hline Md & 16 & - & - & - & - & $1.17-1.53$ & 1.35 \\
\hline
\end{tabular}

Lectotype MLMC 230, left mandible with $\mathrm{p} 4-\mathrm{m} 2+$ $\mathrm{a} 2+\mathrm{a} 3 \quad(\mathrm{p} 4=1.00 \times 0.68 ; \mathrm{m} 1=1.43 \times 0.86 \times 0.99 ;$ $\mathrm{m} 2=1.43 \times 0.90 \times 0.95)$, figured in Viret and Zapfe, Fig. 6a-b, p. 416.

Measurements Table 6

Referred specimens FSL 65716-65718 and FSL 66757-66779: a partial skull, MLMC 418, with preserved P4-M1, 12 maxillae and 16 mandibles, plus several isolated teeth (I, P4, M1, M2, M3, i, a, p4, m1, m2 and $\mathrm{m} 3)$.

Remarks The species Lartetium dehmi is well described in Viret and Zapfe (1952) with abundant illustrations of the specimens. Later, more material was found by Mein in Vieux-Collonges and studied in 1958. We can add a lower incisor, never described, which shows on the dorsal edge two small cuspules separated by light hollows. In this paper, this species is illustrated by some new pictures of maxillae from Vieux-Collonges (Fig. 7). One strikingly distinctive feature is that in L. dehmi, $\mathrm{m} 2$ is longer than $\mathrm{m} 1$, contrasting with most of the shrews where $\mathrm{m} 1$ is longer than $\mathrm{m} 2$.

Lartetium ziegleri Mein and Ginsburg, 2002

Type locality: La Grive L3 (France, Isère), late Middle Miocene (MN7-8)

Table 7 Measurements of Lartetium ziegleri lower dentition from La Grive L3 (in mm)

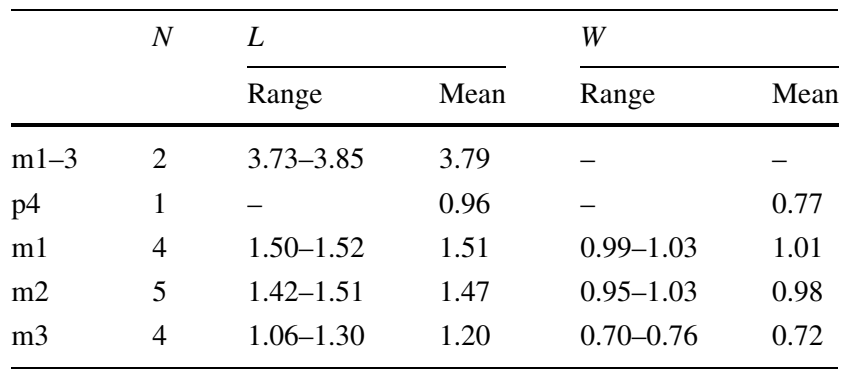

Holotype: Right mandible with $\mathrm{m} 1-\mathrm{m} 3$ and alveoli of $\mathrm{i}$, a1, a2, a3, p4 (FSL 66147)

Paratypes: left maxillary fragment with preserved A5, and alveoli of A1-A4 (FSL 66780); left M1 (FSL 66781).

Referred specimens: FSL 66782-66788, including one maxilla, five mandibles and more than 600 isolated teeth

Measurements Table 7

Diagnosis Lartetium somewhat smaller than $L$. dehmi from Vieux-Collonges, larger than Lartetium prevostianum (Lartet, 1851) and Lartetium petersbuchense Ziegler, 1989 (translated from Mein and Ginsburg 2002).

Emended diagnosis: Lartetium somewhat smaller than L. dehmi (Viret and Zapfe, 1952) larger than Lartetium prevostianum (Lartet, 1851).

Differential diagnosis Lartetium ziegleri is smaller than L. petersbuchense, in contradiction with the original diagnosis (L m1-m3 for L. ziegleri from 3.65 to 3.73 vs. 3.97 for $L$. petersbuchense). L. ziegleri differs from $L$. dehmi in having a lower corpus mandibulae tapering forwards, with a very long antemolar part and a smaller and narrower $\mathrm{m} 3$.

Description The upper dentition is poorly represented. One maxillary fragment (FSL 66780) possesses a preserved A5; this tooth $(0.85 \times 0.78)$ is twice as large as the corresponding tooth in Miosorex grivensis. Two very similar left M1 have been found, they are characterised by a straight labial edge (as in Lartetium petersbuchense from Petersbuch 2) and a low connection between the protocone and the base of the metacone.

The lower dentition shows a mental foramen between the anterior root of $\mathrm{p} 4$ and antemolars; the antemolar part of the mandible is very long. The p4 is short but as high as it is long, with two roots; its labial crest is longer than its lingual one; furthermore the $\mathrm{p} 4$ covers the a3 socket in occlusal view. $\mathrm{m} 1$ and $\mathrm{m} 2$ have similar sizes; their entoconids are well developed and are interrupted without connecting the metaconid basis; on the lingual side, the hypoconid crest joins entoconid at the base of this cuspid. $\mathrm{m} 3$ is posteriorly reduced, but its talonid always presents a slight basin between the crests. The lingual crest is interrupted before joining the metaconid.

Genus Turiasorex van Dam, van der Hoek Ostende, Reumer, 2011

Type species Turiasorex pierremeini van Dam et al. (2011)

Type-locality Casas Altas (Spain), early Late Miocene (MN9)

Turiasorex pierremeini van Dam, van der Hoek Ostende, Reumer, 2011

Figure $8 \mathrm{f}$

Referred specimens La Grive L3: FSL 66868-66671, three isolated teeth M1, $\mathrm{m} 1$ and $\mathrm{m} 2$. La Grive L7: FSL 

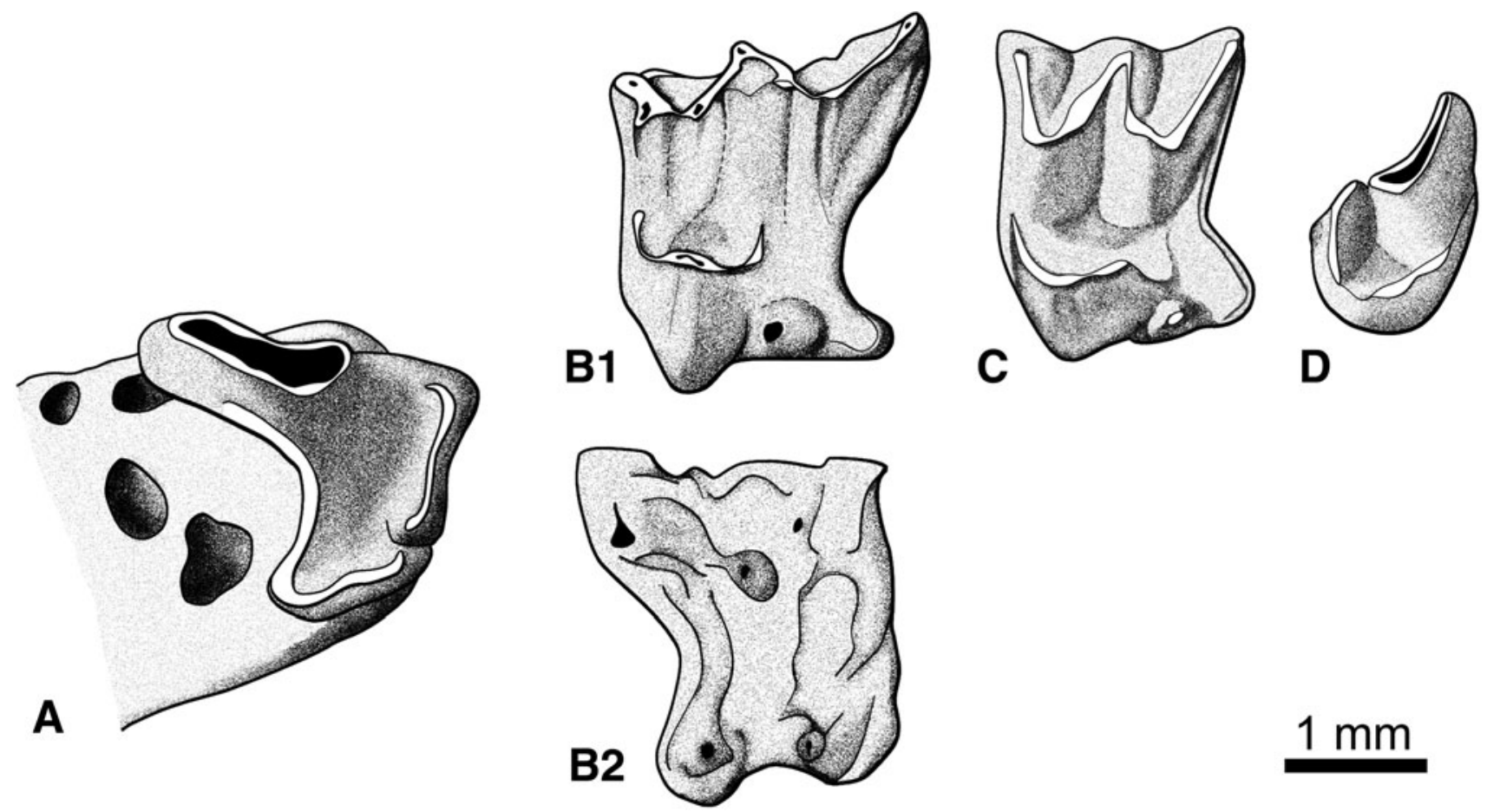

$1 \mathrm{~mm}$

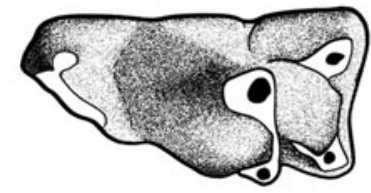

E1
E2

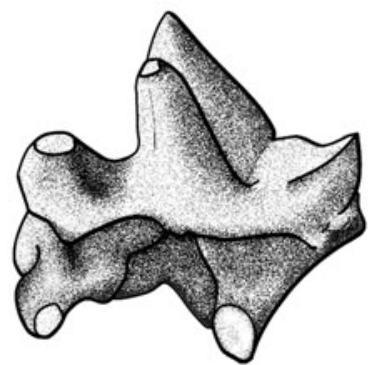

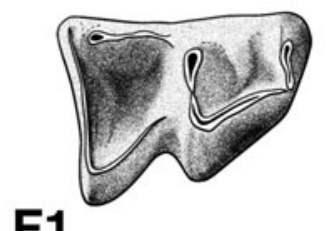

F1

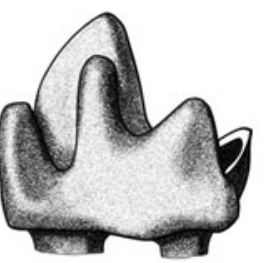

F2

view from below); c left M2, FSL 66791g (occlusal view); d right M3, FSL 66791k (occlusal view); e left m1, FSL 66792a (e1 occlusal view; e2 lingual view); f right m1, FSL 66867 b (f1 occlusal view; f2 lingual view) Grive L3 (f): a right maxillary fragment with P4 and alveoli M1, FSL 66791h (palatal view); b left M1, FSL 667911 (b1 occlusal view, b2

66860-66867, 13 left mandibles, some isolated teeth (I, M1), and one large lower incisor. La Grive M: FSL 66850-66859, four Mx, I, P4, M1, one mandible, m2, m3

Measurements Table 8

Remarks Turiasorex is a new genus of shrew recently described from the Teruel and Calatayud-Daroca basins in the East central Spain; its age is MN7-8 and MN9. In the La Grive collections of the University Lyon 1, this genus is present in fissures L7 and M of La Grive. The remains are rare and co-occur with Miosorex which is hundreds of time more abundant. However, in La Grive, the teeth of Turiasorex being slightly smaller than Miosorex and with different proportions, they can be primarily differentiated by their size. When mandibles are available the two genera can be easily differentiated by the position of the mental foramen located under the anterior root of $\mathrm{m} 1$ in Turiasorex.
Subfamily Allosoricinae Fejfar, 1966

Allosoricinae present very narrow lower molars, with a trigonid much longer than the talonid, two-rooted $\mathrm{p} 4$ vertically implanted; in this tooth, the protoconid is placed in a median position and in the middle of the tooth; the posterolabial crest is thick and the posterolingual crest thin; between these two crests is a small depression. The welldeveloped distal cingulum connects to the posterolabial crest. These characteristic molar features are present in Viretia which is allocated to Allosoricinae.

Viretia nov. gen.

Type species Sorex gracilidens Viret and Zapfe, 1952 Type locality Neudorf Spalte (Devinska Nova Ves, Slovakei Republik), Middle Miocene (MN6) 
Table 8 Measurements of Turiasorex pierremeini from La Grive localities L3 and M (in $\mathrm{mm}$ )

\begin{tabular}{|c|c|c|c|c|c|c|}
\hline & \multirow[t]{2}{*}{ Locality } & \multirow[t]{2}{*}{$N$} & \multicolumn{2}{|l|}{$L$} & \multicolumn{2}{|l|}{$W$} \\
\hline & & & Range & Mean & Range & Mean \\
\hline $\mathrm{P} 4$ & $\mathrm{M}$ & 9 & $1.30-1.48$ & 1.37 & $1.41-1.58$ & 1.53 \\
\hline \multirow[t]{2}{*}{ M1 } & L3 & 2 & $1.32-1.37$ & 1.34 & $1.78-1.80$ & 1.79 \\
\hline & M & 3 & $1.26-1.38$ & 1.31 & $1.71-1.93$ & 1.84 \\
\hline M2 & $\mathrm{M}$ & 4 & $1.12-1.23$ & 1.17 & $1.60-1.71$ & 1.65 \\
\hline M3 & M & 6 & $0.67-0.82$ & 0.78 & $1.30-1.45$ & 1.35 \\
\hline $\mathrm{m} 1-3$ & $\mathrm{M}$ & 5 & $3.40-3.58$ & 3.48 & - & - \\
\hline $\mathrm{p} 4$ & $\mathrm{M}$ & 3 & $0.90-0.95$ & 0.92 & $0.75-0.81$ & 0.77 \\
\hline \multirow[t]{2}{*}{$\mathrm{m} 1$} & L3 & 2 & $1.32-1.35$ & 1.33 & $0.87-0.90$ & 0.88 \\
\hline & $\mathrm{M}$ & 8 & $1.26-1.43$ & 1.33 & $0.87-0.96$ & 0.91 \\
\hline \multirow[t]{2}{*}{$\mathrm{m} 2$} & L3 & 2 & $1.40-1.65$ & 1.52 & $0.81-0.82$ & 0.81 \\
\hline & $\mathrm{M}$ & 9 & $1.20-1.35$ & 1.29 & $0.84-0.94$ & 0.88 \\
\hline $\mathrm{m} 3$ & M & 5 & $1.04-1.09$ & 1.06 & $0.62-0.75$ & 0.70 \\
\hline
\end{tabular}

Other localities Oberdorf (Austria), Franzenbad (Tchek Republik), La Grive M (France)

New localities La Grive L5, L7 (France) studied in this paper.

Derivatio nominis Genus dedicated to Jean Viret, former professor at the University Claude Bernard Lyon and Director of the Natural History Museum of Lyon, who was the first palaeontologist to study the soricids of Neudorf in collaboration with Helmuth Zapfe and also the first to state that this species could pertain to a new genus.

Generic diagnosis Small size shrew characterised by very narrow molars, the molar size strongly decreasing from the first to the last. For all the lower teeth, the trigonid is much longer than the talonid; this talonid is more and more reduced from $\mathrm{m} 1$ to $\mathrm{m} 3$. The $\mathrm{p} 4$ is very narrow with an indistinct metaconid; it is vertically implanted as are the molars (Viret and Zapfe 1952; Fig. 9). The mental foramen is located below p4, between its two roots. The ascending ramus is relatively long and high, and has two well-separated articular facets on the condyle.

Differential diagnosis Viretia differs from Allosorexgenus previously proposed for the species gracilidens (see Ziegler 1998b)—by its much smaller size. The two-rooted narrow and conical lower 4 is nearly symmetrical anteroposteriorly and without overlapping the anterior tooth; in Allosorex, the lingual edge is longer than the labial one and the protoconid curve is stronger than in Viretia. The p4 in Viretia is nearly as high as the protoconid of $\mathrm{m} 1$, but lower in Allosorex. The ascending ramus and condyle show very different patterns. The relative size of lower molars is more contrasted in Allosorex and the teeth are relatively narrower.
Table 9 Measurements of Viretia gracilidens from La Grive L5, L7 and $\mathrm{M}$ (in $\mathrm{mm})$

\begin{tabular}{lllllll}
\hline & $N$ & \multicolumn{2}{l}{$L$} & & \multicolumn{2}{l}{$W$} \\
\cline { 7 - 7 } \cline { 6 - 7 } & & Range & Mean & & Range & Mean \\
\hline $\mathrm{m} 1$ & 1 & - & 1.57 & - & 0.81 \\
$\mathrm{~m} 2$ & 1 & - & 1.46 & - & 0.75 \\
$\mathrm{~m} 3$ & 1 & - & 0.98 & - & 0.44 \\
$\mathrm{P} 4$ & 3 & $1.33-1.53$ & 1.45 & & $1.40-1.47$ & 1.45 \\
$\mathrm{M} 1$ & 1 & - & 1.36 & & - & 1.68 \\
$\mathrm{M} 2$ & 6 & $1.17-1.37$ & 1.26 & & $1.50-1.73$ & 1.64 \\
$\mathrm{M} 3$ & 2 & $0.77-0.80$ & 0.78 & & $1.30-1.30$ & 1.30 \\
\hline
\end{tabular}

Due to the scarcity of specimens the measurements of La Grive localities are given here together

Viretia gracilidens (Viret and Zapfe, 1952)

Figure 8a-e

1952-Sorex gracilidens Viret and Zapfe, p. 418

1966-Sorex (s.1.) gracilidens Viret and Zapfe, p. 239

1998_"Allosorex" gracilidens Ziegler, p.68-69

1999_-"Sorex" gracilidens Mein, p. 30

Lectotype Left mandible with $\mathrm{p} 4-\mathrm{m} 3$ and ascending ramus, NMW C 28, figured in Viret and Zapfe (1952), Fig. 9. (L p4-m3 = 4.6; L m1-m3 = 3.7; $\mathrm{H} / \mathrm{m} 2=1.4$ ).

Paralectotype from Neudorf FSL 66790, right mandible with $\mathrm{m} 2-\mathrm{m} 3$, ascending ramus and condyle $(\mathrm{m} 2=1.22 \times$ $0.60 ; \mathrm{m} 3=0.98 \times 0.44 ; \mathrm{H} / \mathrm{m} 2=1.3)$.

Studied material La Grive L5, L7 and M: FSL 66790FSL 66792, four partial maxillae and isolated teeth.

\section{Measurements Table 9.}

Description of the material from La Grive A maxillary fragment (FSL 66791 e) shows a relatively small infraorbital foramen, situated above the P4. Backwards the foramen lacrymal is small and the bridge between the two foramina is narrow.

Upper teeth $\mathrm{P} 4$ is dominated by a very long buccal edge which makes a near $90^{\circ}$ angle with the anterior edge. The moderately high paracone is extended by a decreasing posterior metastyle crest on the base of the tooth; a basal cingulum is well developed forwards, thinner in the middle part and thicker in the posterior part. The parastyle is completely separated from the paracone; it shows a lingual crest which joins the protocone. The protocone is nearer from the lingual edge; the hypocone is indistinct, incorporated into a lingual cingulum which continues to the posterior edge of the tooth. The two lingual and buccal edges are not parallel. The posterior emargination is huge.

In the M1 from La Grive L5, the buccal edge is much larger than the lingual one, because the metastyle extends far postero-buccally. The very important buccal length of the M1 fits very well the also elongated shape of the lower 
molars, thus supporting the attribution of all specimens to the new genus. The antero-buccal edge is straight. The metacone is twice as big as the paracone. The post-paracone crista joins the pre-metacone crista before the labial edge, so that a little straight mesostyle crista is present; the simple mesostyle is well developed. A protruding parastyle is lacking on the anterior buccal edge. The protocone shows an anterior crest linked with the paracone base and a posterior crest disappears without connection; these two crests make an angle of about $110^{\circ}$. The hypocone is small but well developed, more buccally located than the protocone and not connected to it. The lingual edge of the tooth is sinuous between the protocone and the hypocone base. A short postero-lingual cingulum extends backwards. The posterior emargination is relatively short and restricted to the lingual part of the posterior edge. There are four roots, each located under the main cusps, plus the mark of a fifth one under the mesostyle.

M2 is smaller than M1; the buccal edge is sinuous as in the M1 but the distal cingulum, the posterior emargination and the metastyle are weaker than in M1.

M3 is triangular; the metacone is absent and the metastyle crest follows the posterior edge, connecting to a weak protocone and a protruding parastyle on the buccal edge; the mesostyle shows a clear division into two parts. By comparison, the M3 mesostyle is only superficially divided in the Oberdorf sample (Ziegler 1998b).

Lower teeth One $\mathrm{m} 1$ from La Grive M was briefly mentioned in Mein (1999). It is characterised by a very narrow trigonid; the protoconid is higher than the other cuspids; its tip is curved backwards; the posterior arm of the protoconid ends in the lingual part of the trigonid and is coalescent with the metaconid. This metaconid is higher than the two other lingual cuspids. The buccal cingulum is well marked anteriorly, indistinct in the middle and weak distally. The talonid is short with a flat basin. The anterior arm of the hypoconid ends lingually after the middle of the tooth, and the posterior arm slopes down to the middle of the tooth and then climbs up and joins the entoconid under its tip. On the lingual edge, the entoconid is well marked and joins the metaconid by a curved crest. Because the measurements and the morphology of this $\mathrm{m} 1$ are comparable to those of the lectotype from Devinska Nova Ves (Neudorf), this tooth is attributed to Viretia gracilidens.

Only one tooth from another fissure (La Grive L7) displays a similar morphology but noticeably smaller (perhaps partly due to the corroded enamel) and has been identified as $\mathrm{m} 2$.

No $m 3$ has been recorded in La Grive.

We can compare directly the La Grive material with a right partial mandible from Devinska Nova Ves (Neudorf, FSL 66790). An $\mathrm{m} 3$ is preserved on this mandible. The tooth is very small $(0.98 \times 0.44)$ and as a very low crown.
The trigonid is about three times longer than the talonid. The talonid basin is completely undistinguishable. This mandible (FSL 66790) also preserves the ascending ramus. The measurements of this mandible are height of the coronoid process $=3.79$, width of the internal temporal fossa $=1.35$, height of the condyle $=1.4$, length of the condylar lower facet $=1.3$. In posterior view the condyle has two separate articular facets. The superior one is rounded and higher on the buccal side; the inferior articular facet is slightly divided in two parts and twice as long as high. This inferior articular surface is remarkably strong.

Discussion Viret and Zapfe (1952) recognised this new species only in Devinska Nova Ves (Neudorf) and suggested that it could be a new sub-genus or even a new genus. They gave as particular characteristics the relatively high mandibular ramus with mental foramen under $\mathrm{p} 4$; ascending ramus well developed in length with wide internal temporal fossa; the particularly strong condyle is low, at the level of the teeth. Teeth are particularly narrow, the size of the molars progressively decreasing backwards and characterised by their unusually long trigonid wide open lingually. Weak metaconid close to protoconid. Very reduced $\mathrm{m} 3$. The most remarkable tooth, the two-rooted $\mathrm{p} 4$, is a high cone-shaped unicuspid, bucco-lingually flattened tooth without an accessory cuspule and with a simple basal cingulum, a pattern unknown so far in soricids; moreover, the crown does not overlap the preceding tooth as is the case in other Miocene or recent soricids.

At the moment, upper molars of this form are unknown.

Fejfar (1966) excavated at Devinska Nova Ves; he published pictures of the "holotype" of "Sorex gracilidens"-p4-m1 (Fig. 14d-f) and ascending ramus with condyle (Fig. 13a-d) - together with a newly found $\mathrm{m} 1$ $(1.40 \times 0.76)$. Based on this new material Fejfar (1966) concluded that $S$. gracilidens shows noticeable affinities with his new genus Allosorex from Ivanovce (Slovak Republic, Pliocene, MN15), the holotype of which is a toothless mandible with condyle, for which he created the new subfamily Allosoricinae.

Reumer (1992) outlined the problems of the different subfamilies of Soricinae as did Ziegler (1998b) who also described more precisely and figured an important sample from Oberdorf 4 (Austria; MN4) as "Allosorex" gracilidens which can undoubtedly be referred to the above described material.

Engesser (1972) also described an m1 called 'Soricid II' and compared it with "Sorex" gracilidens. He concluded that there were affinities between the two species (based on the very narrow trigonid, the reduced talonid and the backwardly inclined tip of the protoconid), but because of the size differences, the different location of the mental foramen and the posterior crest connection to the entoconid on $\mathrm{m} 1$, he excluded a direct filiation between these two forms. 
This form is unknown in Vieux-Collonges but it is present and rare in La Grive localities.

Subfamily Paenelimnoecinae Fejfar, Storch \& Tobien, 2006

Unlike Reumer (1992) and van den Hoek Ostende et al. (2009) who proposed to include Paenelimnoecus in the Allosoricinae, we rather follow the point of view of Fejfar et al. (2006) to include the genus in a subfamily of its own. Indeed Paenelimnoecus clearly differs from Allosoricinae by the lack of carnassial specialisations on $\mathrm{m} 1$ and from Crocidosoricinae by the condyle bearing two separated articular facets.

Paenelimnoecus Baudelot, 1972

Type species Paenelimnoecus crouzeli Baudelot, 1972 Type locality Sansan (France, Gers), early Middle Miocene (MN6)

Remarks This genus represents the smallest Middle Miocene soricid; it is as small as the Early Miocene Clapasorex. Two species Paenelimnoecus micromorphus (Doben-Florin, 1964) and Paenelimnoecus crouzeli Baudelot, 1972 are found respectively in Vieux-Collonges and La Grive M and L7.

\section{Paenelimnoecus micromorphus (Doben-Florin, 1964)}

Type locality Wintershof-West (Germany), Early Miocene (MN3).

Studied material Vieux-Collonges: FSL 66793-66800, two maxillae, one I, one P4, two M1, one i, two mandibles with $\mathrm{m} 1-\mathrm{m} 2$ and one humerus; La Grive L3: FSL 66801 and 66802: two mandibles with $\mathrm{m} 1-\mathrm{m} 2$.

Measurements Tables 10 and 11

Description and comparison The strongly curved upper incisor has preserved a second posterior cusplet and shows a yellow-brown pigmentation at the tip of the two cups. This pigmentation is not preserved on the other teeth. The P4 shows a projecting parastyle; its lingual cingulum tapers off backwards; M1 and M2 are quadrangular, M1 being larger than M2. The M1 from Erkertshofen 2 shows a more protruding parastyle and a larger metastyle on the buccal

Table 10 Measurements of Paenelimnoecus micromorphus maxillae from Vieux-Collonges (in $\mathrm{mm}$ )

\begin{tabular}{lllllll}
\hline & $N$ & $L$ & & & & \\
\cline { 7 - 7 } & & Range & Mean & & Range & Mean \\
\hline P4-M2 & 2 & $3.43-3.47$ & 3.45 & & - & - \\
P4 & 2 & $1.10-1.29$ & 1.19 & & $1.31-1.38$ & 1.34 \\
M1 & 4 & $1.10-1.34$ & 1.22 & & $1.22-1.43$ & 1.37 \\
M2 & 2 & $1.10-1.17$ & 1.13 & & $1.32-1.38$ & 1.35 \\
\hline
\end{tabular}

Table 11 Measurements of Paenelimnoecus micromorphus mandibles from Vieux-Collonges ( $\mathrm{VxC}$ ) and La Grive L3 (in mm)

\begin{tabular}{|c|c|c|c|c|c|c|}
\hline & \multirow[t]{2}{*}{ Locality } & \multirow[t]{2}{*}{$N$} & \multicolumn{2}{|l|}{$L$} & \multicolumn{2}{|l|}{$W$} \\
\hline & & & Range & Mean & Range & Mean \\
\hline \multirow[t]{2}{*}{ m1 } & $\mathrm{VxC}$ & 11 & $0.92-1.24$ & 1.13 & $0.48-0.73$ & 0.68 \\
\hline & L3 & 3 & $1.15-1.18$ & 1.17 & $0.65-0.83$ & 0.74 \\
\hline \multirow[t]{2}{*}{$\mathrm{m} 2$} & $\mathrm{VxC}$ & 11 & $0.95-1.21$ & 1.11 & $0.65-0.85$ & 0.7 \\
\hline & L3 & 1 & - & 1.13 & - & 0.74 \\
\hline \multirow[t]{3}{*}{$\mathrm{m} 3$} & $\mathrm{VxC}$ & $4 / 3$ & $0.85-1.03$ & 0.93 & $0.56-0.69$ & 0.62 \\
\hline & Locality & $N$ & $L$ & & $H$ & \\
\hline & & & Range & Mean & Range & Mean \\
\hline i & $\mathrm{VxC}$ & 7 & $1.57-1.83$ & 1.71 & $0.51-0.67$ & 0.58 \\
\hline
\end{tabular}

edge. On the lingual edge, the posterolingual cingulum begins after the end of the protocone and it is not cuspidate (Ziegler 1989; Fig. 6). In our material, the M1 parastyle seems smaller than on the tooth from Erkertshofen 2. On the buccal side, the postparacone crest and the premetacone crest link themselves only at their tips and draw a protruding mesostyle. The lingual wall of the tooth is smooth. The M2 seems proportionally larger. On the maxilla, the lacrymal foramen is above M1 and the infraorbital foramen above P4. One M1 (FSL 66795b: $1.16 \times 1.40$ ) was figured in Mein (1958) under the name Sorex collongensis. This material does not contain an M3, but the maxilla presents three alveoli for the roots. The last buccal alveolus is near the end of the maxilla implying that M3 must be very short.

The mandibular condyle shows two separated articular surfaces. In the lower dentition, $\mathrm{m} 2$ is slightly shorter than $\mathrm{m} 1$ and its paraconid is somewhat lingually bent.

Discussion Paenelimnoecus micromorphus was described from Wintershof-West (MN3). The locality of VieuxCollonges is more recent (MN5) and offers some maxillae fragments, unknown until now. The measurements of the Vieux-Collonges fossils fit very well those of Wintershof despite the more recent age. Two upper molars from Erkertshofen 2 (MN4b) have been ascribed to this species and were briefly described in Ziegler (1989); they notably differ from Vieux-Collonges specimens by being smaller $(\mathrm{M} 1=0.98 \times 0.98$ in Erkertshofen 2 and $\mathrm{M} 1=1.34 \times$ 1.42 and $1.28 \times 1.43$ in Vieux-Collonges). P. truyolsi (Gibert 1975) from MN5 levels in Spain (van den Hoek Ostende et al. 2009) is also smaller.

Paenelimnoecus micromorphus was also found in $\mathrm{La}$ Grive L3. A difference from the Vieux-Collonges P. micromorphus is the position of the mental foramen slightly more anterior, under the anterior root of $\mathrm{m} 1$. This record constitutes the last occurrence for this species which is unknown in later fissures of La Grive despite extensive sampling. 
Paenelimnoecus crouzeli Baudelot, 1972

Type locality Sansan (France, Gers), early Middle Miocene (MN6)

Studied material La Grive L7: FSL 66803-66810, three mandibles and several isolated teeth (i, m1, m2, I, P4, M2). La Grive M: FSL 66811-66820, one I, two maxillae with M1-M2, isolated lower teeth and post-cranial elements such as humeri. It is noted that some specimens (not studied here) from the Forsyth Major collection are stored in the Paleontological Museum of Firenze.

\section{Measurements Tables 12 and 13}

Comparison with P. micromorphus The two species differ primarily in their size, $P$. micromorphus being larger than $P$. crouzeli. The two species have the mental foramen located under the anterior root of $\mathrm{m} 1$. They show a strong spicule under the buccal top of the ascending ramus; the top of the ramus is straight in $P$. crouzeli and somewhat backwardly bent in $P$. micromorphus. $P$. crouzeli differs from $P$. micromorphus in having a distinct cingulum, an ectocingulum and an incomplete lingual cingulum, in lower teeth. $P$. crouzeli also has a biradiculate p4. Furthermore, the $\mathrm{p} 4$ of $P$. micromorphus has two crests joining the tip to the posterior edge whereas only a buccal crest is present in $P$. crouzeli. In $P$. crouzeli a faint crest runs

Table 12 Measurements of Paenelimnoecus crouzeli maxillae from La Grive $M$ (in $\mathrm{mm}$ )

\begin{tabular}{lllllll}
\hline & $N$ & $L$ & & & $W$ & \\
\cline { 7 - 7 } & & Range & Mean & & Range & Mean \\
\hline P4-M2 & 2 & $2.83-2.87$ & 2.85 & & - & - \\
P4 & 5 & $0.87-1.01$ & 0.95 & & $0.85-1.00$ & 0.95 \\
M1 & $6 / 3$ & $0.97-1.05$ & 1.01 & & $1.10-1.16$ & 1.14 \\
M2 & 6 & $0.90-0.97$ & 0.94 & & $1.06-1.19$ & 1.13 \\
M3 & 1 & - & 0.75 & - & 0.40 \\
\hline
\end{tabular}

Table 13 Measurements (in mm) of Paenelimnoecus crouzeli mandibles from La Grive localities L7 and M

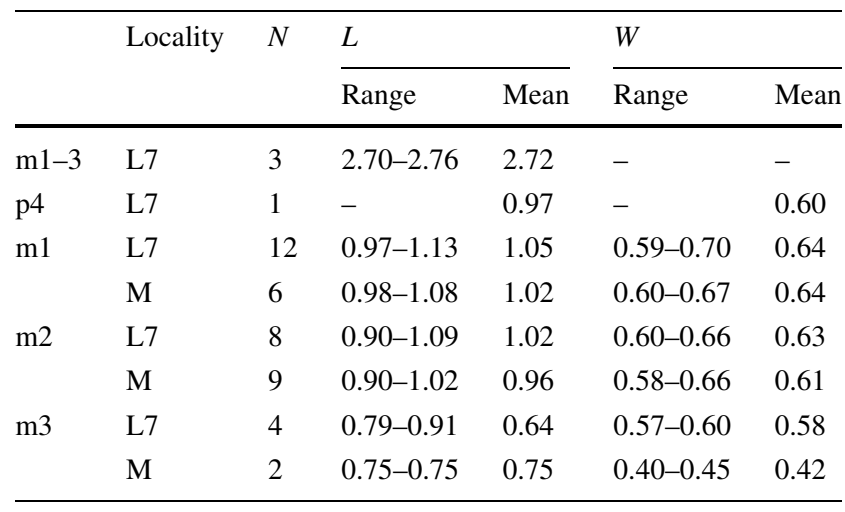

alongside the lingual edge from the trigonid to the rear, whereas $P$. micromorphus shows a real cuspid. On the maxillae of $P$. crouzeli, the lacrymal foramen is just above the M1-M2 border. The lingual edge of P. micromorphus is smooth whereas it is scalloped for P. crouzeli.

Remarks The species $P$. crouzeli was recently revised by Engesser (2009) based on the material from Sansan. This tiny shrew is present in the vicinity of Lyon only in La Grive fissures. More generally, concerning the genus, Paenelimnoecus is a tiny genus of soricid with a very long temporal occurrence: it is known in Europe from the Early Miocene of Wintershof-West (Germany, MN3) until the late Pliocene.

Subfamily Soricinae G. Fischer, 1814

Genus Hemisorex Baudelot, 1967

Type species Hemisorex robustus Baudelot, 1967

Hemisorex robustus Baudelot, 1967

Figure 9

Studied material Vieux-Collonges: FSL 66822-66830, eight mandibles with $\mathrm{p} 4, \mathrm{~m} 1, \mathrm{~m} 2, \mathrm{~m} 3$ and ascending rami, plus isolated lower and upper incisors. La Grive L3: FSL 66831-66832, two maxillae and one mandible. La Grive L7: FSL 66833-66843, I, maxillae, M1, M2, mandibles, p4, m1, m2, m3. La Grive M: FSL 66844-66849, six maxillae including one with preserved M1-M3, 15 mandibles with ascending rami, including three with preserved $\mathrm{m} 1-\mathrm{m} 3$, plus some isolated lower teeth.

Emended diagnosis, Maxilla The origin of the temporal fossa is located behind M2 (as in Dinosorex); the beginning of the zygomatic arch is at the same level as the posterior part of M2; the infra orbital canal is long; the infra-orbital foramen is large, located above the M1, as in Miosorex (in contrast this hole is above P4 in the Heterosoricinae, Crocidura and Sorex araneus). The rounded lacrymal foramen ends above the M1-M2 border. The molars are quadrangular with a tiny posterior emargination, and they are lacking of hypocone. The $\mathrm{P} 4$, however, possesses a tiny hypocone. The two arms of protocone crest form a very flat angle, nearly $160^{\circ}$. For lower teeth see Engesser (2009).

Measurements Table 14

Description Hemisorex robustus was well described by Engesser (2009) based on the mandibles from Sansan. Engesser (2009) described only the inferior part of the dentition but fragments of maxillae are present in the La Grive fissures (but not in Vieux-Collonges).

Lower dentition The mental foramen is located under the protoconid of $\mathrm{m} 1$; the mandibular foramen is in the middle of the ascending ramus (illustrated by Engesser 2009, Fig. 13). Vieux-Collonges yielded only two isolated incisors; they are pigmented on their tip, the tip being slightly upwardly curved and having a secondary cusplet. 

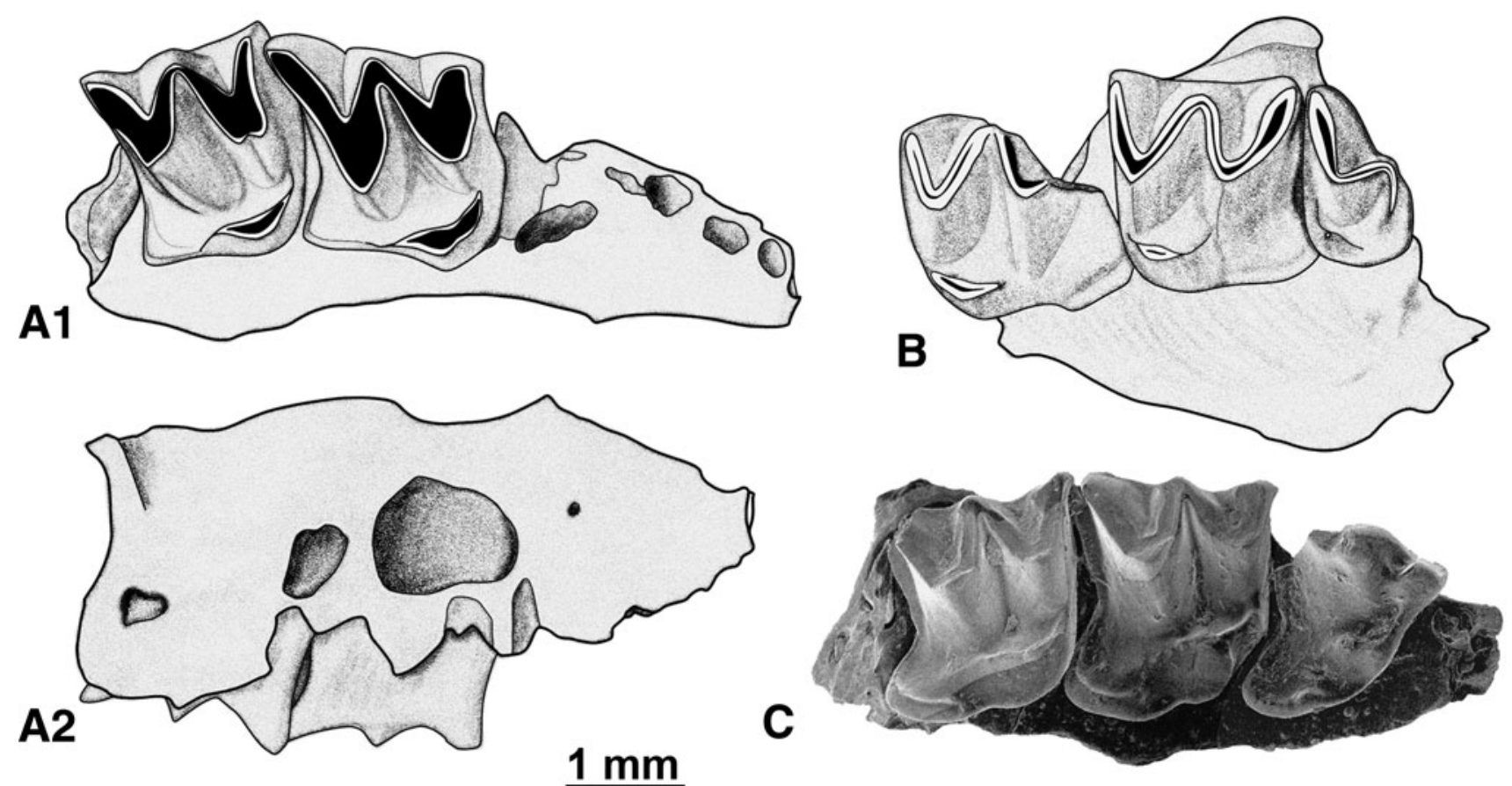

Fig. 9 Hemisorex robustus Baudelot, 1967 from La Grive M (ab) and L7 (c): a right partial maxilla with M1-M2 and alveoli, FSL 66846a (a1 palatal slightly oblique view; a2 labial view); b left partial

maxilla with M1-M3, FSL 66844 (palatal view); c right maxilla with P4-M2, FSL 66835a (palatal view)

Hemisorex robustus possesses only one antemolar before p4 (preserved on the FSL 66825 mandible). The $\mathrm{m} 1$ and $\mathrm{m} 2$ are of the same size. On the $\mathrm{m} 3$, the buccal crest is located in the middle of the tooth (not on the edge as $\mathrm{m} 1$ and $\mathrm{m} 2$ ); in the lingual edge, there is a very low crest descending to the metaconid base.

Upper dentition The upper dentition is unknown in Vieux-Collonges except for some upper incisors; the following is consequently mainly based on the specimen yielded by La Grive localities. On the maxilla, in front of P4, two alveoli for the antemolars are visible but without the contact with the incisor. Among the specimens from Vieux-Collonges five left and two right upper incisors have been found; they differ from Miosorex upper incisors in being larger, less curved and having a heavy red-dark pigmentation on theirs tips. $\mathrm{P} 4$ is relatively wide. It has three roots: two small ones on the buccal side and a long one on the lingual edge. The parastyle is large and separated from the paracone; the protocone is weak and has an anterior crest parallel to the anterior edge. A posterior crest descends towards the small hypocone. The paracone is strong and bulbous; it is continued by a crest. M1 and M2 are similar; M2 is only a little smaller than M1 and its posterior emargination is wider; the two molars are quadrangular, with a weak posterior emargination; all the teeth lack parastyles and metastyles; a continuous cingulum, without any cusps, runs from the posterior to the lingual edges. The metacone is only slightly stronger than the

paracone. The mesostyle is short, wide and simple. M3 is smaller than the two first molars. Its anterior edge is covered by the M2 metastyle. The anterior part of the tooth has a strong paracone and a small independent protocone. The buccal crest is $\mathrm{V}$-shaped and extends onto the posterobuccal edge by a small crest.

Discussion The genus Hemisorex, rare in Sansan where it was initially described, is present in Vieux-Collonges and in all fissures from La Grive with consistently coloured tips on incisor and molars. The comparison with the mandibles of Vieux-Collonges shows no significant differences between the samples from Sansan, Vieux-Collonges and La Grive despite the different ages of the localities. VieuxCollonges seems to be the oldest locality where this genus occurs and $\mathrm{La}$ Grive $\mathrm{M}$ the youngest. Throughout this period the morphology and size of Hemisorex seem to have been relatively stable. However, based on the measurement of the specimens (Table 14) a slight increase of the size is likely across the late Early and Middle Miocene.

\section{Conclusions}

At the beginning of the Miocene new soricids genera-not reported in the Oligocene levels-are present in Limagne; all exhibit mandibles with three antemolars before a tworooted p4 and pigmented teeth. Later in Saulcet and Chavroches, the same genera are present with generally 
Table 14 Measurements of Hemisorex robustus Vieux-Collonges (VxC) and La Grive localities L3, L7, and M (in mm)

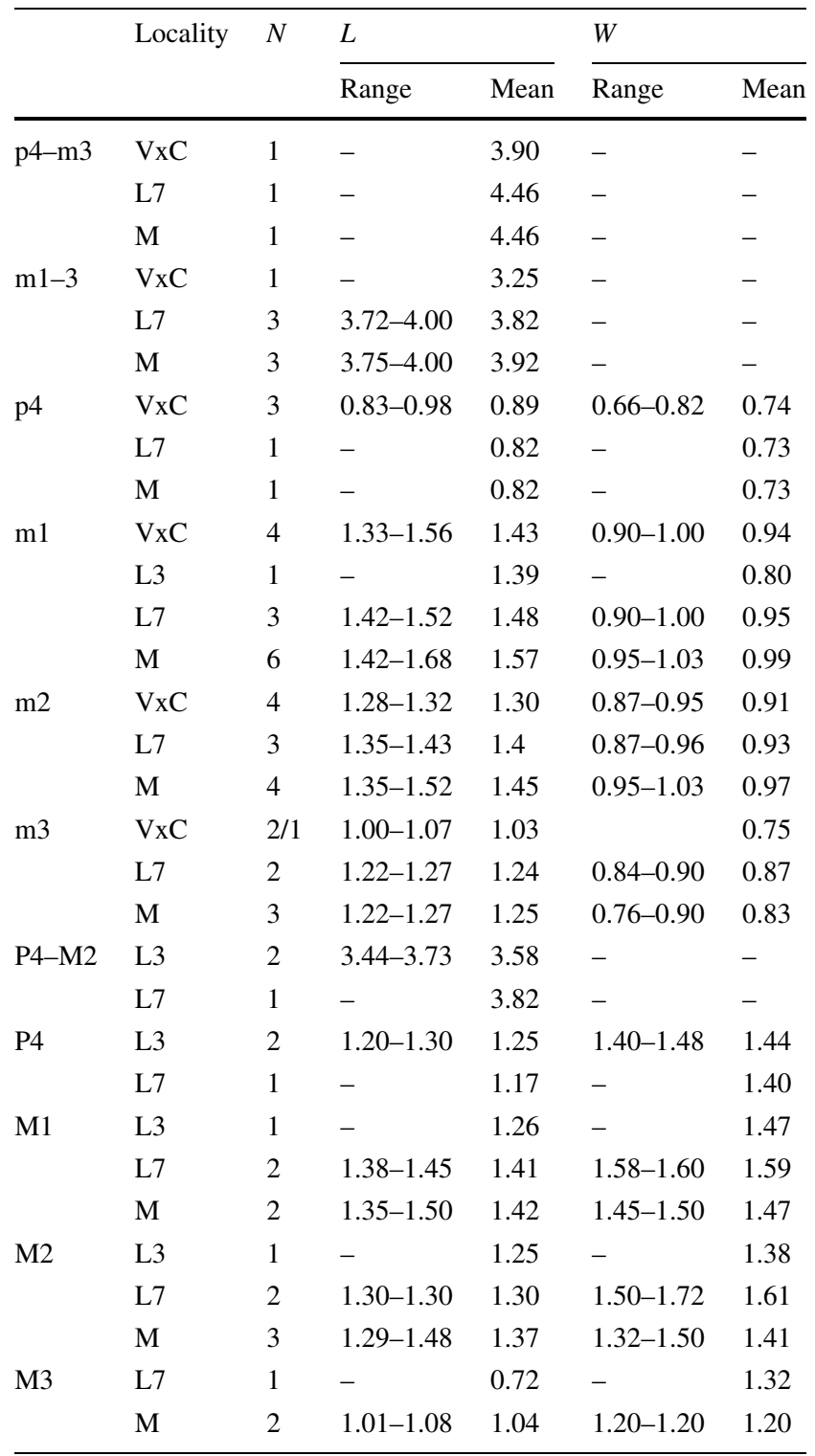

larger size. Some teeth of Soricella are documented in Chavroches and testify to the beginning of a decrease in the number of antemolars (Soricella, Meingensorex). However, the changes in the pattern of cingula observed in Crocidosorex-which genus is now restricted to its Early Miocene type-locality (Hugueney and Maridet 2011)—occur apparently later than the upper levels of the Montaigu-leBlin quarry.

The Oligocene large-sized genera Srinitium and Ulmensia seem to have disappeared and, moreover, the Heterosoricinae, which were present in the late Oligocene of Limagne, are almost unknown there (even if present in Germany and Spain) so that the Early Miocene soricid fauna encompasses only small and medium sized soricids.
The soricid assemblages of the late Early and Middle Miocene localities testify to a drastic turnover during the Early Miocene (Fig. 10). The genera present in Limagne are not known farther than the MN3 level (except Soricella which is reported by Ziegler 1989 from MN4). Important changes in soricid faunas occur in MN3.

The assemblage of Vieux-Collonges is characterised by predominance of shrews compared with other small mammals and by a new association of soricid genera including Miosorex, Lartetium, Paenelimnoecus, Hemisorex and Dinosorex. This generic assemblage will persist in the faunal assemblages yielded by the Middle Miocene localities, but with different species, except for Hemisorex robustus which is the only species to persist till MN7-8 in La Grive localities.

The reasons of such a drastic change in soricid assemblages remain unexplained so far. As stated by Reumer (1995) climatic parameters, such as humidity or annual precipitations, may play a crucial role in constraining the diversity of insectivores. However, other environmental factors such as the vegetation and the presence of stretches of fresh water also likely influence their diversity for they can be directly linked to the local insect assemblages which are the primary food resource of insectivores.

Consequently, difference in soricid assemblages in the earliest Miocene localities on the one hand, and the late Early and Middle Miocene localities on the other hand might reflect a climatic and environmental shift occurring between the Aquitanian and the Burdigalian, as also suggested by Costeur et al. (2012). Indeed, the micromammals' assemblage of Vieux-Collonges with its predominance of shrews coincides well with the Miocene climatic optimum at the same period (17-14 Ma: e.g. Böhme 2003; Costeur and Legendre 2008). The occurrence of Pteropodidae bats in Vieux-Collonges (unpublished data) confirms the presence of fleshy fruits on a year-round basis and consequently the existence of significantly humid and warm climatic conditions.

Following the end of this Miocene climatic optimum, the Middle Miocene soricid assemblages remain composed of the same genera suggesting a relative continuity of regional environmental conditions from the late Early and through the Middle Miocene. The percentage of soricids is even higher in La Grive faunas (Mein 1984), especially in La Grive L7 and La Grive M; it could possibly suggest even more humid conditions. The presence of the semiaquatic insectivore Asthenoscapter in the localities L3, L7 and L5 is coherent with this hypothesis and indicates the persistence, along the Middle Miocene, of fresh water/ swamps nearby these localities.

Such a persistence or increase of humidity along the Middle Miocene in the area of Lyon was already proposed by Maridet et al. (2000) based on faunal composition changes in the stratified fissure filling of Four locality (in 


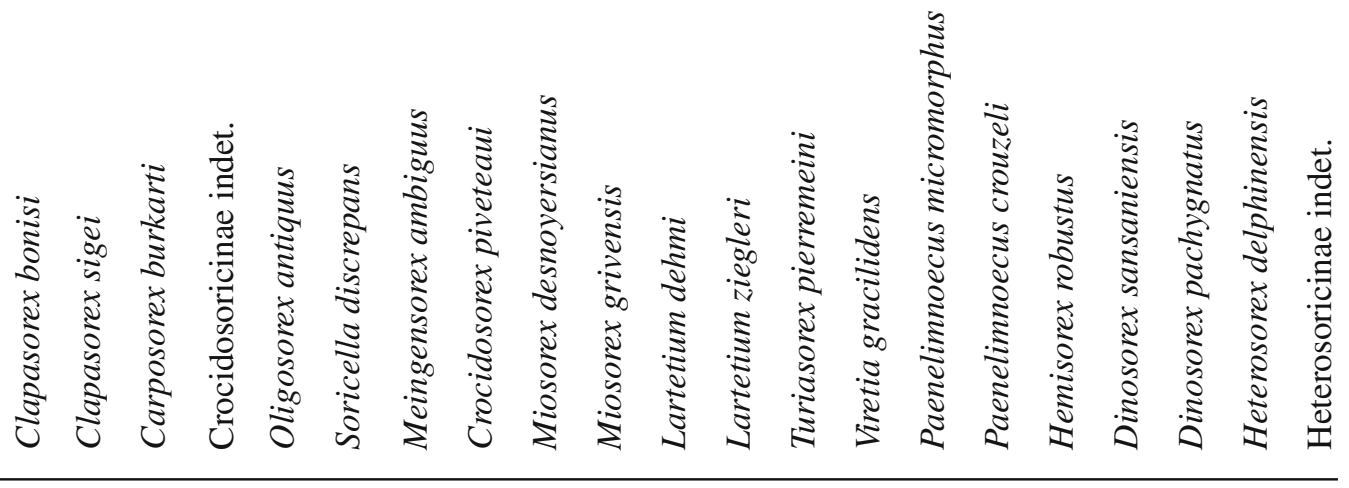

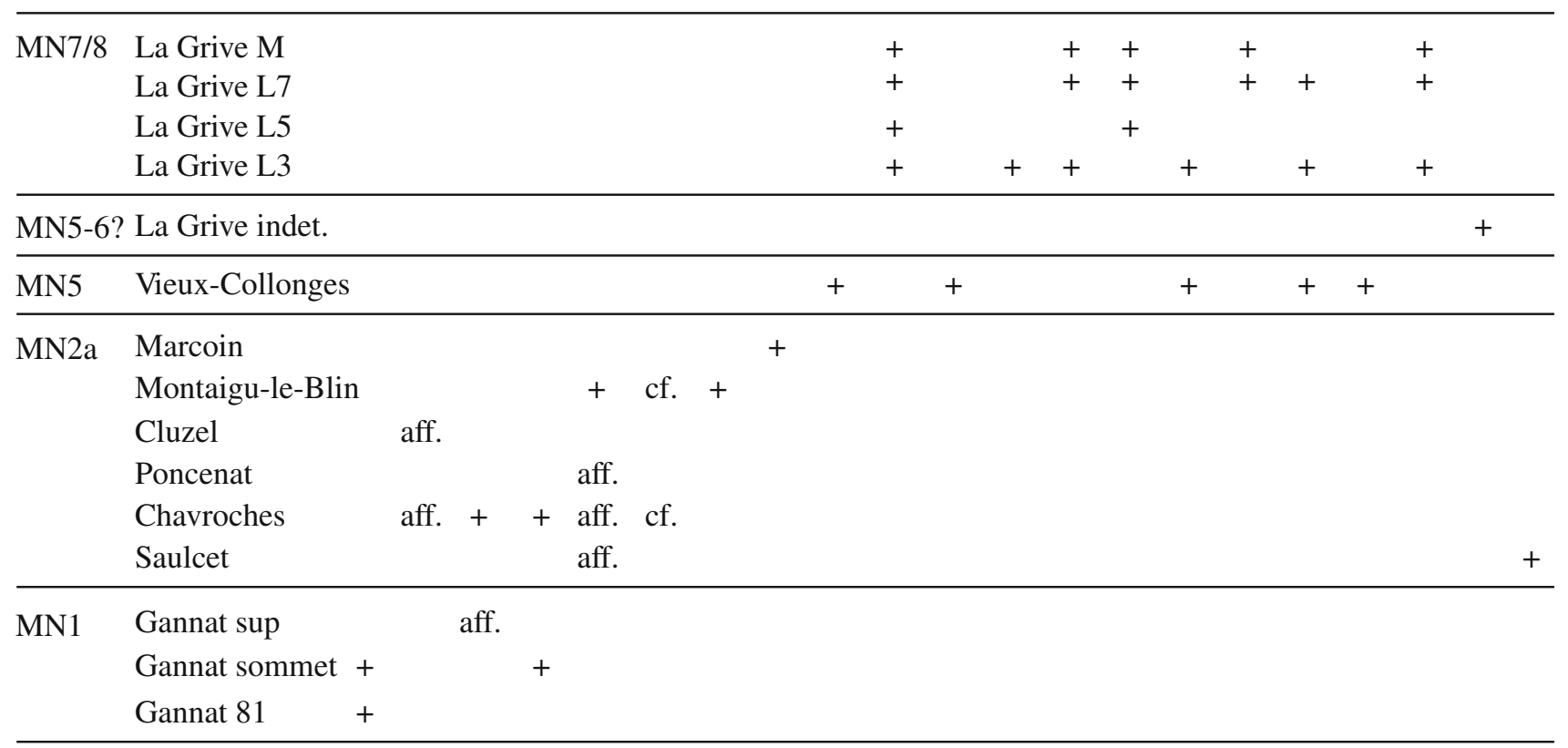

Fig. 10 Chronological distribution of soricids in the studied localities

the vicinity of La Grive) and suggests the existence of a "green corridor". This hypothesis is coherent with the presence of the large Rhodanian sea-channel (Rögl 1999; Popov et al. 2004) in the late Middle Miocene, close to La Grive sites, which could explain the peculiar environmental evolution toward more humid conditions in contrast with other European regions.

Acknowledgments We are very pleased to celebrate a long friendship with our colleague Burkart. The Basel Museum and both Lyon's University and Museum have been in close contact in the past 80 years through the active correspondence between J. Viret and $\mathrm{H}$. Helbing, H.G. Stehlin, H. Schaub and later J. Hürzeler, and Burkart Engesser with us. We sincerely thank Loïc Costeur, Chief Editor of the Swiss Journal of Palaeontology who invited us to participate to this volume. Many thanks are due to M. Pickford for his friendly improvement of our poor English language. We are grateful to D. Jammot who began to work on Soricids and took pictures of the Miocene material during the sixties: some of these are used in this paper. Many thanks are due to G. Sirven for his long and unfailing participation in our research as well by numerous casts as by careful maintenance and numerous repairs to our old microscopes. A. Armand made SEM photographs of the Montaigu material. We also thank L. Costeur, as curator of the collections of the Museum of Basel, for the loan of the material from Saulcet and Chavroches, A. Prieur, in charge of the collections of Lyon 1 University, for the loan of the material from La Grive and Vieux-Collonges. D. Berthet, in charge of the collections of the Museum of Lyon, loaned the material from Chavroches but, unfortunately, following the cataloguing of Mein's material from Vieux Collonges in this Museum, the specimens were for the moment not available for study. We are also thankful to two reviewers who provided interesting and detailed comments that contributed to improving this study. OM's research is supported by the Chinese National Natural Science Foundation (41050110135) and a Research Fellowship for International Young Researchers from the Chinese Academy of Sciences (2009Y2BZ3).

\section{References}

Baudelot, S. (1972). Etude des Chiroptères, Insectivores et Rongeurs du Miocène de Sansan (Gers). Unpublished Ph.D. Thesis, University of Toulouse.

Berthet, D. (2003). Le genre Cainotherium (Mammalia, Artiodactyla); Etude morphométrique, révision systématique, implications évolutives et paléogéographiques, extinction. Documents Lyon, 159, 1-205. 
Böhme, M. (2003). The Miocene climatic optimum: evidence from ectothermic vertebrate of Central Europe. Palaeogeography, Palaeoclimatology, Palaeoecology, 195, 389-401.

Costeur, L., \& Legendre, S. (2008). Mammalian communities document a latitudinal environmental gradient during the miocene optimum in western Europe. Palaios, 23, 280-288.

Costeur, L., Maridet, O., Peigné, S., \& Heizmann, E.P.J. (2012). Palaeoecology and palaeoenvironment of the Aquitanian locality Ulm-Westtangente (MN2, Lower Freshwater Molasse, Germany). Swiss Journal of Palaeontology, this volume.

Crochet, J. Y. (1975). Diversité des insectivores soricidés du Miocène inférieur de France. Colloques Internationaux du Centre National de la Recherche Scientifique, 218, 631-652.

Dannelid, E. (1998). Dental adaptations in shrews. In J. M. Wójcik \& M. Wolsan (Eds.), Evolution of Shrews (pp. 157-174). Bialowieza: Mammal Research Institute, Polish Academy of Science.

Deperet, C. (1892). La faune de mammifères miocènes de La Grive Saint-Alban (Isère). Archives du Museum d'Histoire Naturelle de Lyon, 5, 1-93.

Engesser, B. (1972). Die obermiozäne Säugetierfauna von Anwil (Baselland). Tätigkeitsberichte Naturforschender Gesellschaft Basel, B, 28, 37-363.

Engesser, B. (1975). Revision der europaïschen Heterosoricinae (Insectivora, Mammalia). Eclogae geologicae Helvetiae, 68, 649-671.

Engesser, B. (2009). The insectivores (Mammalia) from Sansan (Middle Miocene south-western France). Schweizerische Paläontologische Abhandlungen, 128, 1-91.

Engesser, B., \& Storch, G. (2008). Latest Oligocene Didelphimorphia, Lipotyphla, Rodentia and lagomorpha (Mammalia) from Oberleichtersbach, Rhön Mountains, Germany. Courrier Forschung-Institut Senckenberg, 206, 185-251.

Fejfar, O. (1966). Die plio-pleistozänen Wirbeltierfaunen von Hajnacka und Ivanovce (Slowakei), CSSR. V. Allosorex stenodus n.g., n. sp. aus Ivanovce. Neues Jahrbuch für geologie und Palaeontologie Abhandlungen, 123, 221-248.

Fejfar, O., Storch, G., \& Tobien, H. (2006). Gundersheim 4, a third Ruscinian micromammalian assemblage from Germany. Palaeontographica A, 278, 97-111.

Furió, M., Santos-Cubedo, A., Minwer-Barakat, R., \& Agustí, J. (2007). Evolutionary history of the African soricid Myosorex (Insectivora, Mammalia) out of Africa. Journal of Vertebrate Paleontology, 27, 1018-1032.

Gaillard, C. (1915). Nouveau genre de musaraigne dans les dépôts miocènes de La Grive Saint-Alban (Isère). Annales de la Société Linnéenne de Lyon, 62, 83-98.

Hugueney, M. (1974). Gisements de petits mammifères dans la région de Saint-Gérand-le-Puy (stratigraphie relative). Revue Scientifique du Bourbonnais, 1974, 52-68.

Hugueney, M. (1997). Biochronologie mammalienne dans le Paléogène et le Miocène inférieur du centre de la France: synhèse réactualisée. In J.-P Aguilar, S. Legendre \& J. Michaux (Eds.), Actes du Congrès BiochroM'97 (vol. 21, pp. 417-430). Montpellier : Mémoires et Travaux de l'E.P.H.E.

Hugueney, M., Berthet, D., Escuillié, F., \& Rival, J. (2006). Eomyids (Rodentia, Mammalia) in the St-Gérand-le-Puy area (Allier, France; MN2a). Beiträge zur Paläontology, 30, 205-221.

Hugueney, M., \& Maridet, O. (2011). Early Miocene soricids (Insectivora, Mammalia) from Limagne (Central France): new systematic comparisons, updated biostratigraphic data and evolutionary implications. Geobios, 44, 225-236.

Lopatin, A. V. (2004). New Early Miocene shrews (Soricidae, Mammalia) from Kazakhstan. Paleontological Journal, 38, 211-219.

López-Antoñanzas, R., \& Mein, P. (2009). First detailed description of Hispanomys bijugatus Mein and Freudenthal, 1971 (Rodentia,
Cricetodontinae) from the Upper Aragonian of La Grive-SaintAlban (France): biostratigraphical implications. Geobios, 42, 783-796.

Major, F. (1899). On fossil dormice. Geological Magazine, London, $6,492-501$

Maridet, O. (2003). Révision du genre Democricetodon (Mammalia, Rodentia, Cricetinae) et dynamique des faunes de rongeurs du Néogène d'Europe occidentale : évolution, paléobiodiversité et paléobiogéographie. Unpublished Ph.D Thesis, University of Lyon 1.

Maridet, O., Berthet, D., \& Mein, P. (2000). Un nouveau gisement karstic polyphasé miocène moyen de Four (Isère) : étude des Cricetidae (Mammalia, Rodentia) et description de Democricetodon fourensis nov. sp. Géologie de la France, 2000, 71-79.

Maridet, O., \& Sen, S. (2012). Les Cricetidae du gisement de Sansan, in: Peigne, S., Sen, S. (Eds.), Les mammifères du gisement de Sansan. Mémoires du Muséum d'Histoire Naturelle de Paris, numéro spécial. (In french with extended english abstract).

Mein, P. (1958). Les mammifères de la faune sidérolithique de VieuxCollonges. Nouvelles Archives du Muséum d'Histoire naturelle de Lyon, 5, 1-122.

Mein, P. (1975). Résultats du groupe de travail des vertébrés: Biozonation du Néogène méditerranéen à partir des mammifères. In J. Senes (Ed.), Report on activity of the R.C.M.N.S. working groups (1971-1975) (pp. 78-81, table). Bratislava.

Mein, P. (1984). Composition quantitative des faunes de mammifères $\mathrm{du}$ Miocène moyen et supérieur de la région Lyonnaise. Paléobiologie continentale, 14, 339-346.

Mein, P. (1999). European Miocene mammal biochronology. In G. E. Rössner \& K. Heissig (Eds.), The Miocene land mammals of Europe (pp. 25-38). München: Verlag Dr. Friedrich Pfeil.

Mein, P., \& Ginsburg, L. (2002). Sur l'âge relatif des différents dépôts karstiques miocènes de La Grive-Saint-Alban (Isère). Cahiers scientifiques du Muséum d'Histoire naturelle, 2, 7-47.

Popov, S. V., Rögl, F., Rozanov, A. Y., Steininger, F. F., Shcherba, I. G., \& Kovac, M. (2004). Lithological-Paleogeographic Maps of Paratethys. Courier Forschungsinstitut Senckenberg, 250, 1-46.

Reumer, J. W. F. (1984). Ruscinian and early Pleistocene Soricidae (Insectivora, Mammalia) from Tegelen (The Netherlands) and Hungary. Scripta Geologica, 73, 1-173.

Reumer, J. W. F. (1987). Redefinition of the Soricidae and the Heterosoricidae (Insectivora, Mammalia), with the description of the Crocidosoricinae, a new subfamily of Soricidae. Revue de Paléobiologie, 6, 189-192.

Reumer, J. W. F. (1992). The taxonomic position of the genus Paenelimnoecus Baudelot, 1972 (Mammalia, Soricidae): a resurrection of the subfamily Allosoricinae. Journal of Vertebrate Paleontology, 12, 103-106.

Reumer, J.W.F. (1995). The evolution of shrews (Mammalia, Soricidae): a key role for humidity. Geobios, M.S.18, 367-372.

Rögl, F. (1999). Circum-Mediterranean Miocene Paleogeography. In G. E. Rössner \& K. Heissig (Eds.), The Miocene land mammals of Europe (pp. 39-48). München: Verlag Dr. Friedrich Pfeil.

van Dam, J. A. (1997). The small mammals from the Upper Miocene of the Teruel-Alfambra region (Spain)/palaeobiology and paleoclimatic reconstructions. Geologica ultraiectina, 156, 1-204.

van Dam, J. A., van den Hoek Ostende, L. W., \& Reumer, J. W. F. (2011). A new short-snouted shrew from the Miocene of Spain. Geobios, 44, 299-307.

van den Hoek Ostende, L. W. (2001) Insectivore faunas from the Lower Miocene of Anatolia. Part 6: Crocidosoricinae (Soricidae). Scripta Geologica, 122, 47-81.

van den Hoek Ostende, L.W. (2003). Insectivores (Erinaceomorpha, Soricomorpha, Mammalia) from the Ramblian of the DarocaCalamocha area. In N López Martínez, P. Pelaez-Campomanes \& M. Hernandez Fernandez (Eds.), En torno a fosiles de 
mamiferos: datacion, evolucion y paleoambiente (vol. 1, pp. 281-310). Madrid: Coloquios de Paleontologia Volumen Extraordinario.

van den Hoek Ostende, L. W., Furio, M., \& Garcia-Paredes, I. (2009). New data on Paenelimnoecus from the middle Miocene of Spain support the shrew subfamily Allosoricinae. Acta Palaeontologica Polonica, 54(1), 159-164.

Viret, J., \& Zapfe, H. (1952). Sur quelques Soricidés miocènes. Eclogae Geologicae Helvetiae, 44, 411-426.

Ziegler, R. (1989). Heterosoricidae und Soricidae (Insectivora, Mammalia) aus dem Oberoligozän und Untermiozän Süddeutschlands. Stuttgarter Beiträge zur Naturkunde, Serie B, 154, 1-73.

Ziegler, R. (1998a). Marsupiala und Insectivora (Mammalia) aus den oberoligozänen Spaltenfüllungen Herrlingen 8 und Herrlingen 9 bei Ulm (Baden-Würtemberg). Senckenbergiana Lethaea, 77, 101-143.
Ziegler, R. (1998b). Wierbeltiere aus dem Unter-Miozändes LignitTagebaues Oberdorf (West-steirisches Becken, Österreich): 5- Marsupiala, Insectivora und Chiroptera. Annalen des Naturhistorischen Museum Wien, 99A, 43-97.

Ziegler, R. (2003). Shrews (Soricidae, Mammalia) from the Middle Miocene karstic fissure fillings of Petersbuch near Eichstätt, Southern Franconian Alb (Bavaria). Paläontologische Zeitschrift, 77, 303-322.

Ziegler, R., Dahlman, T., \& Storch, G. (2007). 4- Marsupialia, Erinaceomorpha and Soricomorpha (Mammalia). In G. DaxnerHöck (Ed.), Oligo-Miocene vertebrates from the Valley of Lakes (Central Mongolia). Morphology, phylogenetic and stratigraphic implications (vol. 108A, pp. 53-164). Wien: Annalen des Naturhistorisches Museums in Wien. 